\title{
Positionspapier zur praktischen Umsetzung der apparativen Differenzialtherapie der akuten respiratorischen Insuffizienz bei COVID-19
}

\author{
Deutsche Gesellschaft für Pneumologie und Beatmungsmedizin e.V. (DGP) \\ Position Paper for the State of the Art Application of Respiratory \\ Support in Patients with COVID-19
}

\author{
German Respiratory Society
}

Autoren

M. Pfeifer ${ }^{1,2,3}$, S. Ewig ${ }^{4}$, T. Voshaar ${ }^{5}$, W. Randerath $^{6,7}$, T. Bauer ${ }^{8}$, J. Geiseler ${ }^{9}$, D. Dellweg ${ }^{10}$, M. Westhoff ${ }^{11,12}$, W. Windisch ${ }^{12,13}$, B. Schönhofer ${ }^{14}$, S. Kluge ${ }^{15}$, P. M. Lepper ${ }^{16}$

Institute

1 Klinik und Poliklinik für Innere Medizin II, Universitätsklinik Regensburg, Regensburg

2 Abteilung für Pneumologie, Fachklinik für Lungenerkrankungen Donaustauf

3 Krankenhaus Barmherzige Brüder, Klinik für Pneumologie und konservative Intensivmedizin, Regensburg

4 Thoraxzentrum Ruhrgebiet, Department of Respiratory and Infectious Diseases, EVK Herne and AugustaKrankenanstalt Bochum, Bochum

5 Schwerpunkt Pneumologie, Allergologie, Klinische Immunologie, Zentrum für Schlaf- und Beatmungsmedizin, Krankenhaus Bethanien, Moers

6 Institut für Pneumologie an der Universität zu Köln, Köln

7 Klinik für Pneumologie, Krankenhaus Bethanien, Solingen

8 Lungenklinik Heckeshorn, Helios Klinikum Emil von Behring $\mathrm{GmbH}$, Berlin

9 Medizinische Klinik IV: Klinik für Pneumologie, Beatmungs- und Schlafmedizin, Klinikum Vest GmbH, Paracelsus-Klinik, Marl

10 Fachkrankenhaus Kloster Grafschaft GmbH, Akademisches Lehrkrankenhaus der PhilippsUniversität Marburg, Schmallenberg Grafschaft

11 Klinik für Pneumologie, Lungenklinik Hemer, Hemer

12 Universität Witten-Herdecke, Witten

13 Klinik für Pneumologie, Klinikum Köln-Merheim, Kliniken der Stadt Köln, Lehrstuhl für Pneumologie der Universität Witten-Herdecke, Köln

14 Pneumologische Praxis und pneumologischer Konsildienst im Klinikum Agnes Karll Laatzen, Klinikum Region Hannover, Laatzen

15 Klinik für Intensivmedizin, Universitätsklinikum Hamburg-Eppendorf, Hamburg
16 Innere Medizin V - Pneumologie, Allergologie, Beatmungs- und Umweltmedizin, Universitätsklinikum des Saarlandes, Homburg/Saar

Bibliografie

DOI https://doi.org/10.1055/a-1157-9976 |

Online-Publikation: 22.4.2020

Pneumologie 2020; 74: 337-357

(c) Georg Thieme Verlag KG Stuttgart · New York ISSN 0934-8387

Korrespondenzadresse

Prof. Dr. med. Torsten Bauer, Lungenklinik Heckeshorn,

Helios Klinikum Emil von Behring $\mathrm{GmbH}$, Berlin,

Walterhöferstraße 11, 14165 Berlin

torsten.bauer@helios-gesundheit.de

\section{ZUSAMMENFASSUNG}

Vor dem Hintergrund der Pandemie durch Infektionen mit dem SARS-CoV-2 hat die Deutsche Gesellschaft für Pneumologie und Beatmungsmedizin (DGP e.V.) federführend in Kooperation mit weiteren Verbänden ein Expertenteam benannt, um die zur Zeit drängenden Fragen zu Therapiestrategien im Umgang mit COVID-19-Patienten, die an akut respiratorischer Insuffizienz (ARI) leiden, zu beantworten. Das Positionspapier basiert auf dem momentanen aktuellen Wissen, das sich täglich weiterentwickelt. Viele der publizierten und zitierten Studien bedürfen weiterer Überprüfungen, auch weil viele kein übliches Review-Verfahren durchlaufen haben Daher unterliegt auch dieses Positionspapier einer ständigen Überprüfung und wird in Zusammenarbeit in der Zusammenarbeit mit den anderen Fachgesellschaften weiterentwickelt. 
Dieses Positionspapier wurde in die folgenden fünf Themenfelder gegliedert:

1. Pathophysiologie der akuten respiratorischen Insuffizienz bei Infektionen mit SARS-CoV-2 bei Patienten ohne Immunität

2. Zeitlicher Verlauf und Prognose der akuten respiratorischen Insuffizienz im Laufe der Erkrankung

3. Sauerstoff-Insufflation, High-Flow Sauerstoff, nicht-invasive Beatmung und invasive Beatmung unter besonderer Berücksichtigung der infektiösen Aerosolbildung

4. Nicht-Invasive Beatmung bei der ARI

5. Versorgungskontinuum zur Behandlung der ARI

Zentrale Punkte wurden hierbei als Kernaussagen und Feststellungen herausgehoben. Bezüglich pathophysiologischer Aspekte der akuten respiratorischen Insuffizienz (ARI) verläuft die pulmonale Infektion mit SARS-CoV-2 COVID-19 in drei Phasen: Frühe Infektion, pulmonale Manifestation und schwere hyperinflammatorische Phase.

Der fortgeschrittene COVID-19-induzierte Lungenschaden weist häufig Unterschiede zu den bekannten Veränderungen entsprechend der Definition des Acute Respiratory Distress Syndrome (ARDS) nach den Berlin-Kriterien auf.

In einem pathophysiologisch plausiblen - zur Zeit aber noch nicht histopathologisch untermauerten - Modell wird in zwei Typen (L-Typ und H-Typ) unterschieden, die einer frühen und späten Phase entsprechen. Diese Unterscheidung kann für die apparative Differenzialtherapie der ARI erwogen werden.

Die Einschätzung des Ausmaßes der ARI soll durch eine arterielle oder kapilläre Blutgasanalyse bei Raumluft erfolgen und die Errechnung des Sauerstoffangebotes (bemisst sich aus den Variablen der Sauerstoffsättigung, des Hb-Wertes, der Hüfner'schen Korrekturzahl sowie des Herzminutenvolumens) beinhalten.

Durch Aerosole ist eine Übertragung von infektiösen, Virenhaltigen Partikeln prinzipiell möglich. Offene Systeme bzw. Leckage-Systeme (sog. vented Masken) können die Abgabe von respirablen Partikeln erhöhen. Prozeduren, bei denen das invasive Beatmungssystem geöffnet werden muss, sowie die endotracheale Intubation sind mit einem erhöhten Infektionsrisiko verbunden.

Der Schutz des Personals durch persönliche Schutzausrüstung soll sehr hohe Priorität haben, weil die Angst vor Ansteckung kein primärer Intubationsgrund sein darf. Bei Einhaltung der Vorgaben zu Schutzausrüstung (Augenschutz, FFP2- bzw. FFP-3 Maske, Kittel) kann eine Inhalationstherapie, nasale High Flow (NHF) -Therapie, eine CPAP-Therapie oder eine NIV nach jetzigem Kenntnisstand vom Personal ohne erhöhtes Infektionsrisiko durchgeführt werden.

Ein signifikanter Anteil der respiratorisch insuffizienten Patienten präsentiert sich mit einer relevanten Hypoxämie, die häufig auch durch eine hohe inspiratorische Sauerstofffraktion (FiO2) inklusive NHF nicht vollständig korrigiert werden kann.
In dieser Situation können die CPAP/NIV-Therapie unter Verwendung einer Mund-Nasen-Maske oder eines Beatmungshelms als Therapieeskalation durchgeführt werden, solange die Kriterien für eine endotracheale Intubation nicht erfüllt sind.

Die NIV bei akuter hypoxämischer Insuffizienz sollte auf der Intensivstation oder in einer vergleichbaren Struktur mit entsprechender personeller Expertise erfolgen. Unter CPAP/NIV kann es zu einer raschen Verschlechterung kommen. Aus diesem Grund soll ein ständiges Monitoring unter ständiger Intubationsbereitschaft gewährleistet sein. Kommt es unter CPAP/NIV zur weiteren Progression des ARI, sollte ohne zeitliche Verzögerung die Intubation und nachfolgende invasive Beatmung erfolgen, wenn keine DNI-Order vorliegt.

Bei Patienten, bei denen eine invasive Beatmung unter Ausschöpfung aller leitliniengerechter Maßnahmen nicht ausreicht, um eine ausreichende Sauerstoffaufnahme und $\mathrm{CO}_{2}$-Abgabe zu gewährleisten, soll ein extrakorporales Lungenersatzverfahren erwogen werden (ECMO).

\section{ABSTRACT}

Against the background of the pandemic caused by infection with the SARS-CoV-2, the German Society for Pneumology and Respiratory Medicine (DGP e.V.), in cooperation with other associations, has designated a team of experts in order to answer the currently pressing questions about therapy strategies in dealing with COVID-19 patients suffering from acute respiratory insufficiency (ARI).

The position paper is based on the current knowledge that is evolving daily. Many of the published and cited studies require further review, also because many of them did not undergo standard review processes. Therefore, this position paper is also subject to a continuous review process and will be further developed in cooperation with the other professional societies.

This position paper is structured into the following five topics:

1. Pathophysiology of acute respiratory insufficiency in patients without immunity infected with SARS-CoV-2

2. Temporal course and prognosis of acute respiratory insufficiency during the course of the disease

3. Oxygen insufflation, high-flow oxygen, non-invasive ventilation and invasive ventilation with special consideration of infectious aerosol formation

4. Non-invasive ventilation in ARI

5. Supply continuum for the treatment of ARI

Key points have been highlighted as core statements and significant observations. Regarding the pathophysiological aspects of acute respiratory insufficiency (ARI), the pulmonary infection with SARS-CoV-2 COVID-19 runs through three phases: early infection, pulmonary manifestation and severe hyperinflammatory phase.

There are differences between advanced COVID-19-induced lung damage and those changes seen in Acute Respiratory Distress Syndromes (ARDS) as defined by the Ber- 
lin criteria. In a pathophysiologically plausible - but currently not yet histopathologically substantiated - model, two types (L-type and H-type) are distinguished, which correspond to an early and late phase. This distinction can be taken into consideration in the differential instrumentation in the therapy of ARI.

The assessment of the extent of ARI should be carried out by an arterial or capillary blood gas analysis under room air conditions and must include the calculation of the oxygen supply (measured from the variables of oxygen saturation, the $\mathrm{Hb}$ value, the corrected values of the Hüfner number and the cardiac output). In principle, aerosols can cause transmission of infectious viral particles. Open systems or leakage systems (so-called vented masks) can prevent the release of respirable particles. Procedures in which the invasive ventilation system must be opened, and endotracheal intubation must be carried out are associated with an increased risk of infection.

The protection of personnel with personal protective equipment should have very high priority because fear of contagion must not be a primary reason for intubation. If the specifications for protective equipment (eye protection, FFP2 or FFP-3 mask, gown) are adhered to, inhalation therapy, nasal high-flow (NHF) therapy, CPAP therapy or
NIV can be carried out according to the current state of knowledge without increased risk of infection to the staff. A significant proportion of patients with respiratory failure presents with relevant hypoxemia, often also caused by a high inspiratory oxygen fraction (FiO2) including NHF, and this hypoxemia cannot be not completely corrected. In this situation, CPAP/NIV therapy can be administered under use of a mouth and nose mask or a respiratory helmet as therapy escalation, as long as the criteria for endotracheal intubation are not fulfilled.

In acute hypoxemic respiratory insufficiency, NIV should be performed in an intensive care unit or in a comparable unit by personnel with appropriate expertise. Under CPAP/NIV, a patient can deteriorate rapidly. For this reason, continuous monitoring with readiness to carry out intubation must be ensured at all times. If CPAP/NIV leads to further progression of ARI, intubation and subsequent invasive ventilation should be carried out without delay if no DNI order is in place.

In the case of patients in whom invasive ventilation, after exhausting all guideline-based measures, is not sufficient, extracorporeal membrane oxygenation procedure (ECMO) should be considered to ensure sufficient oxygen supply and to remove $\mathrm{CO}_{2}$.

\section{Einleitung}

Vor dem Hintergrund der Pandemie durch Infektionen mit dem SARS-CoV-2 hat die Deutsche Gesellschaft für Pneumologie und Beatmungsmedizin (DGP e. V.) federführend in Kooperation mit weiteren Verbänden ein Expertenteam benannt, um die offenen Fragen zum Umgang mit COVID-19-Patienten in einem Stadium zu beantworten, in dem soweit zum jetzigen Zeitpunkt absehbar keine Überbelastung der Krankenhäuser entstehen wird (Stand: 15.04.2020). Aufgrund der Wirksamkeit der epidemiologischen Maßnahmen, wie z. B. der sozialen Distanzierung durch eine Ausgangsbeschränkung, ist zurzeit mit einer Verlangsamung und Abschwächung der Pandemie in Deutschland zu rechnen [1].

Somit wurde größten Wert auf die Richtigkeit der Aussagen auch außerhalb einer Pandemiesituation gelegt, und die Kernaussagen wurden in einem aufwendigen Konsensusprozess zwischen den Autoren abgestimmt. Dieses Manuskript versteht sich als Ergänzung, Fortführung und Impulsgeber für einen fachübergreifenden Konsens, basierend auf bestehenden Leitlinien [2-5].

In den bisherigen Publikationen zu COVID-19 findet sich eine bemerkenswerte Heterogenität unterschiedlicher Begleiterscheinungen der Infektion mit SARS-CoV-2. Dies liegt an verschiedenen Definitionen bestimmter Krankheitszustände (z. B. Schock), unterschiedlichen - aber nicht benannten Schweregraden, unterschiedlichen Zeitpunkten der Erkrankung und unterschiedlichen Populationen. Dies erschwert eine Vergleichbarkeit. Es kommt hinzu, dass derzeit Information sehr rasch publiziert werden und die beschriebenen Patientengruppen zum Teil nur einige wenige Individuen umfassen.

Das Manuskript wurde in einem AWMF (Arbeitsgemeinschaft der Wissenschaftlichen Medizinischen Fachgesellschaften e.V.) - konformen Prozess erstellt und ist in 5 Stellungnahmen, die inhaltlich auf einander abgestimmt wurden, gegliedert. Zentrale Punkte werden als Kernaussagen und Feststellungen herausgehoben. Das Manuskript basiert auf dem aktuellen Kenntnisstand über COVID-19, der durch die zunehmende Patientenzahl in Deutschland kurzfristig noch besser werden wird. Aus diesem Grund ist eine Aktualisierung bereits bei Erscheinen geplant.

\section{Methode}

Die Empfehlung basiert auf dem Konsensus einer Expertengruppe vor dem Hintergrund einer selektiven Literaturrecherche. Die Experten wurden vom Vorstand der Deutschen Gesellschaft für Pneumologie und Beatmungsmedizin (DGP) auf dem Boden ihrer Erfahrungen mit der medizinischen Fragestellung und ihrer Erfahrung in der strukturierten Konsensusfindung nach AWMF Kriterien - ernannt.

Die einzelnen Kapitel wurden vorab festgelegt und durch Autorenteams bearbeitet. Die Autorenteams (jeweils 2-3 Autoren) bekamen den Auftrag, eine Textvorlage und Kernaussagen zu formulieren und die Konsensfindung zunächst in der Kleingruppe herzustellen. Je Themenfeld konnten bis zu 3 Kernaussagen formuliert werden. Die Autoren, die nicht der Bearbeitung der Kapitel zugeteilt waren, wurden aufgefordert, Einlassungen vor der Konsensfindung zu vermeiden. 
Es wurde die den Kernaussagen zugrundeliegende Literatur, basierend auf der aktuellen Datenlage, nach den Richtlinien des Centers for Evidence Based Medicine bewertet. Die Kernaussagen wurden den Vorgaben für eine AWMF-konforme Leitlinie entsprechend dabei mit den Formulierungen gemäß einem „Grade of Recommendation“(GOR) versehen. Eine Grad A-Empfehlung entspricht in der Formulierung einem „soll“, eine Grad B-Empfehlung einem „sollte“ und eine Grad 0-Empfehlung einem „kann“. Darüber wurden Feststellungen hervorgehoben, die nicht graduiert, aber konsentiert wurden.

Um dieses Ziel zu erreichen, wurden alle Empfehlungen in einem gemeinsamen Manuskript zusammengefasst, das in $4 \mathrm{di}$ gitalen Delphi-Runden (13.04.2020, 14.04.2020, 15.04.2020 und 16.04.2020 als online Konferenz) bearbeitet wurde. Eine Übersicht zu den einzelnen Empfehlungen und Feststellungen sowie die Zustimmung der Expertengruppe zu dem Manuskript wurde am Ende der letzten Delphi-Runde erarbeitet.

Aufgrund der Aktualität der Empfehlung wurde eine gemeinsame Pressemitteilung in 2 Delphi-Runden (7.4.2020 und 8.4.2020) konsentiert und über die Fachgesellschaft kommuniziert. Eine Pressekonferenz fand aufgrund der Reisebeschränkungen in digitaler Form am 17.04.2020 statt.

Das Manuskript wird zunächst als Positionspapier der Deutschen Gesellschaft für Pneumologie und Beatmungsmedizin (DGP e. V.) und dem kooperierenden Verband Pneumologischer Kliniken (VPK e. V.) online publiziert.

\section{Stellungnahme 1:}

\section{Pathophysiologie der akuten}

respiratorischen Insuffizienz bei Infektionen mit SARS-CoV-2 bei Patienten ohne

Immunität (Pfeifer, M.; Ewig, S.; Voshaar, T.)

\subsection{Allgemein}

Die COVID-19-Erkrankung, ausgelöst durch die Infektion mit dem humanpathogenen Corona-Virus SARS-CoV2 und erstmals Ende Dezember in China beschrieben, hat sich zu einer weltweiten Pandemie entwickelt [6-8]. Dabei verläuft die Erkrankung nach den aktuellen Studien bei ca. $80 \%$ der positiv getesteten Personen mild, bei $20 \%$ schwerer mit Zeichen einer hypoxischen respiratorischen Insuffizienz und macht bei ca. $5 \%$ ist eine intensivmedizinische Behandlung erforderlich [9]. Die berichtete Letalität beträgt zwischen 1 und 10\% [9] (https://coronavirus.jhu.edu/map.html). Alle diese Zahlen beziehen sich allerdings auf die Anzahl der positiv getesteten Personen und stellen aufgrund der deutlich höher angenommenen Dunkelziffer der Infizierten eine Überschätzung dar.

SARS-CoV-2 wird primär durch eine Tröpcheninfektion übertragen (droplet transmission); inwieweit auch Tröpfchenkerne (airborne transmission) oder Übertragungen durch Kontakte (sog. Schmierinfektionen) eine zusätzliche Rolle spielen, ist nicht abschließend geklärt.

Das Virus bindet an den Angiotensin-Converting-Enzyme-2 Rezeptor in der Lunge, einer Membran-gebundenen Aminopeptidase der alveolaren Epithelzellen $[10,11]$. Damit ist die
Lunge das primäre Zielorgan des Virus. Die primäre virale Replikation erfolgt im Bronchialepithel der oberen Atemwege im Bereich des Nasopharynx, eine weitere Multiplikation im Bereich der unteren Atemwege und in der gastrointestinalen Mukosa $[12,13]$. Einige der Infektionen werden in diesem Stadium immunologisch kontrolliert und bleiben asymptomatisch.

COVID-19 verläuft in 3 Phasen, die wie folgt beschrieben werden: Frühe Infektion, pulmonale Manifestation und schwere hyperinflammatorische Phase $[14,15]$ ( $\triangleright$ Abb. 1). Während der frühen infektiösen Phase infiltriert das Virus das Lungenparenchym und beginnt zu replizieren; es erfolgt eine Entzündungsreaktion mit lokaler Vasodilatation, erhöhter endothelialer Permeabilität und einem Leukozyten-Recruitment [16]. Diese Herd-Pneumonie führt zu einer Hypoxämie und zu kardio-vaskulären Stressreaktionen. Die aktuellen Daten zeigen, dass kardiovaskuläre Vorerkrankungen und eine arterielle Hypertonie starke Risikofaktoren für einen letalen Ausgang von COVID-19 sind [6].

Die Erkrankung ist durch eine Lymphozytopenie gekennzeichnet, die eine wesentliche pathognomonische Relevanz für die Erkrankung einnimmt. Diese entsteht durch eine Apoptose $[6,7,17]$. Möglich ist auch, dass präexistierende Antikörper gegen andere Coronaviren im Sinne eines „antibody dependent enhancement" wirksam werden $[18,19]$. Die prolongierte Lymphozytopenie ist mit einer ungünstigen Prognose assoziiert [6, 17].

Die starke systemische Inflammation ist gekennzeichnet durch einen Zytokinsturm, mit einem Anstieg von Interleukin (IL)-6, IL-2, IL-7, Tumor necrosis factor (TNF)- $\alpha$, Interferon- $\gamma$, inducible protein (IP)-10, Monocyte chemoattractant protein (MCP)-1, Macrophage inflammatory protein (MIP) 1- $\alpha$, Granulocyte-colony stimulating factor (G-CSF), C-reaktives Protein (CRP), Procalcitonin und Ferritin [6,20-22].

Von prognostischer Relevanz ist die erhöhte bzw. ansteigende Konzentration von Interleukin-6 und Ferritin [21, 22]. In retrospektiven klinischen Untersuchungen zeigten verstorbene COVID-19-Patienten signifikant höhere Werte von IL-6, Ferritin und CRP [22]. Weitere prognostische Marker sind die D-Dimere und das Troponin [21,22].

Als Folge dieser schweren primär lokalen Inflammation kann es zu einer schweren Schädigung des Lungenparenychms mit den Folgen der progredienten respiratorischen Insuffizienz kommen. Im weiteren Verlauf kann als Folge der systemischen Inflammationsreaktion ein Multiorganversagen auftreten. In pathologisch-anatomischen Untersuchungen konnten z. B. bei SARS auch eine Vaskulitis sowie Thrombosierungen der kleinen Gefäße gezeigt werden [23]. Inwiefern diese Phänomene bei einer Infektion mit SARS-CoV2 zusätzlich eine Rolle spielen, ist noch nicht geklärt.

\subsection{COVID-19 und respiratorische Insuffizienz}

Der Schweregrad der respiratorischen Insuffizienz wird bestimmt durch eine Interaktion zwischen 3 Faktoren: 1) dem Schweregrad der Infektion, der Immunantwort, der Funktionalität und den Komorbiditäten, 2) der ventilatorischen Reaktion des Patienten auf die Hypoxämie (Atemantrieb) und 3) der Zeit 


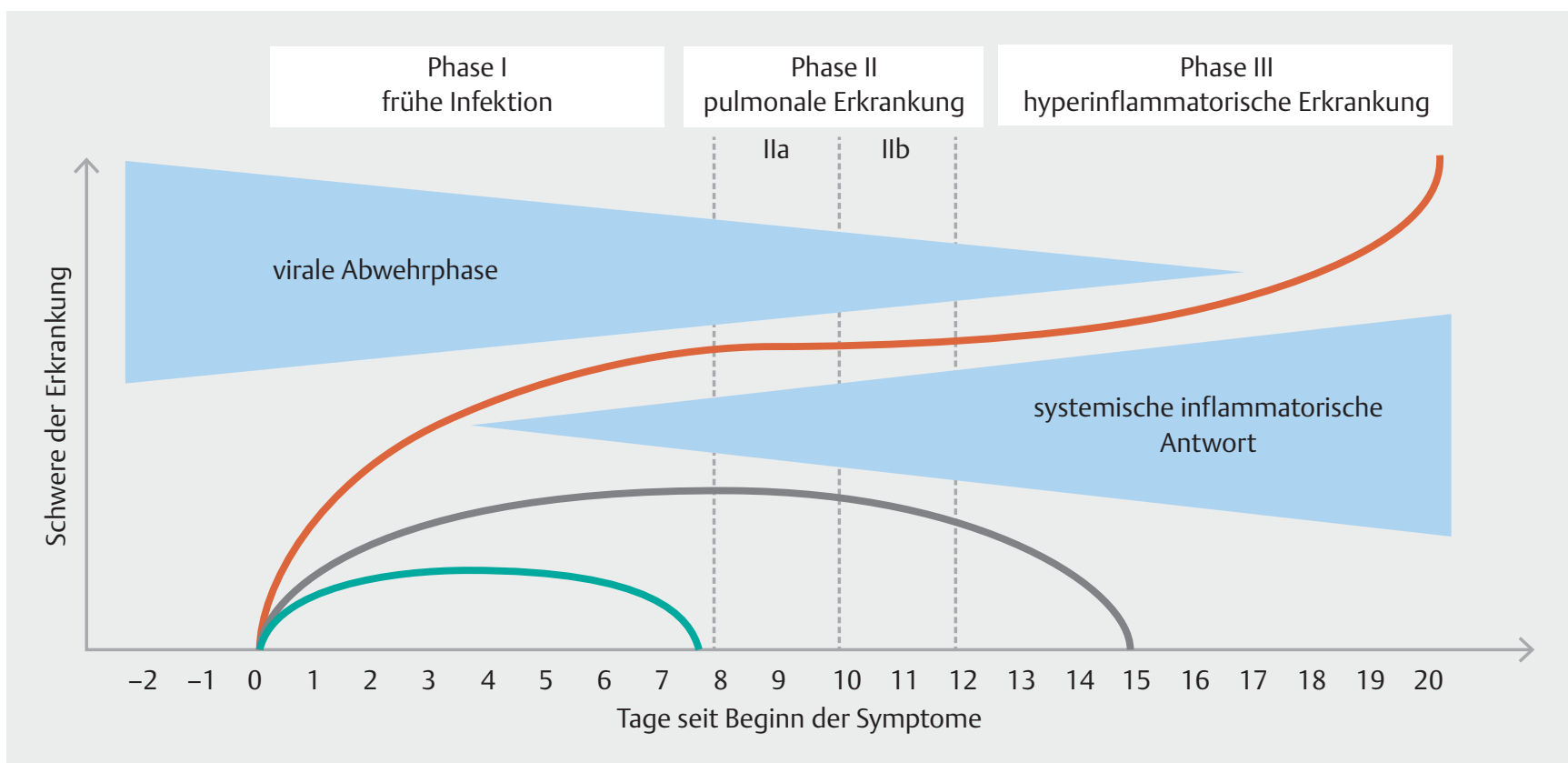

- Abb. 1 Bedeutung der viralen Abwehr und der systemischen inflammatorischen Antwort für die Klinik von Patienten mit COVID-19. Klinische Verläufe von COVID-19 (leicht: grün; schwer: grau; kritisch: rot) werden im zeitlichen Verlauf dargestellt [14, 15].

zwischen den ersten Symptomen und dem Beginn der klinischen Behandlung.

Die Entzündung des Lungengewebes zu Beginn der Erkrankung ist radiologisch in der Computertomografie (CT) der Lunge gekennzeichnet durch fokale, meist beidseitige, pleuranah gelegene sog. Milchglasherde mit Bevorzugung der Mittelund Unterfelder [24-27]. Bei einem Teil der Patienten zeigt sich dann im weiteren Verlauf eine zunehmende Verdichtung im Sinne von Konsolidierungen, die, nach radiologischen Methoden gemessen, zu einer Erhöhung des Lungengewichtes führt [28]. Nicht auszuschließen ist dabei, dass diese Veränderungen durch eine zusätzliche nosokomiale Pneumonie verursacht werden.

Pathophysiologisch ist die respiratorische Insuffizienz primär geprägt durch eine milde bis schwere hypoxische respiratorische Insuffizienz. Im Verlauf der Erkrankung aber zeigen einige Patienten rezidivierend erhebliche $\mathrm{CO}_{2}$-Anstiege. Patienten, die in dieser Phase der Erkrankung intubiert und beatmet werden, haben eine erhöhte alveolo-arterielle Sauerstoffdifferenz (auch unter Berücksichtigung hoher inspiratorischer Sauerstofffraktionen und bei der Annahme eines respiratorischen Quotienten von 0.85) sowie eine auffällig hohe Differenz zwischen arteriellem und endtidalem $\mathrm{CO}_{2}$. Entsprechend den radiologischen Veränderungen lassen sich nach Gattinoni et al. [29] 2 in zeitlicher Abfolge auftretende CT-Manifestationen abgrenzen, eine sog. COVID-19-Pneumonie Typ L und Typ H (siehe unten).

Die Definition eines acute respiratory distress syndomes (ARDS) nach den Berlin-Kriterien kann in beiden Manifestationsformen erfüllt sein; es hat sich jedoch gezeigt, dass die COVID-19-Pneumonie v.a. im frühen Stadium (Typ L), aber auch im späten Stadium (Typ H) wesentliche Unterschiede zu den bekannten Veränderungen eines ARDS aufweist, wie dieses zum Beispiel im Rahmen eines septischen Schocks oder einer bakteriellen Pneumonie zu beobachten ist. In der Folge wird ein Modell beschrieben, das auf CT-Untersuchungen basiert und zum aktuellen Zeitpunkt weder klinisch noch histopathologisch validiert wurde.

\subsection{COVID-19-Pneumonie Typ L}

Diese frühe Phase, die vom Patienten mit Sauerstoffunterstützung kompensiert werden kann, wird von Gattinoni et al. [29] als COVID-19 Pneumonie Typ L bezeichnet. Das L steht für:

- Low (low elastance, d. h. hohe Compliance)

- Low Ventilations/Perfusions-Mismatch

- Low Lungengewicht mit geringer entzündlicher Flüssigkeitseinlagerung, dem radiologischen Korrelat der Milchglasverdichtungen und keinen oder wenigen Konsolidierungen. Somit besteht bei diesem Typ auch ein geringes Rekrutierungspotenzial.

In dieser Phase liegt zwar nach der Berlin-Definition funktionell und radiologisch ein ARDS vor, das sich aber von einem ARDS im Sinne eines diffusen Alveolarschadens (DAD, diffuse alveolar damage) unterscheidet. Bei einem DAD wäre die alveoläre Funktionseinheit geschädigt, zusammen mit einem Verlust der Alveolarstabilität sowie der Ausbildung eines alveolären und interstitiellen Ödems. Bisher gibt es keine systematischen Untersuchungen von COVID-19-Patienten, die in dieser Phase verstorben sind, in denen pathologisch-anatomische mit bildgebenden Befunden korreliert worden wären. Aus pathophysiologischer Sicht muss jedoch die sogenannte COVID-19-TYP LPneumonie anders als ein ARDS gesehen werden. Dies hat aus unserer Sicht erhebliche Implikationen für die Indikationsstel- 
lung zur apparativen Differenzialtherapie der akuten respiratorischen Insuffizienz bei COVID-19.

In der Frühphase der pulmonalen Infektion steht die Hypoxämie im Vordergrund. Als wesentlicher Unterschied zum klassischen ARDS, bei dem durch die Schädigung der Lunge eine deutliche Abnahme der Compliance zu beobachten ist, zeigt sich bei der COVID-19-Pneumonie eine erhaltene Elastizität der Lunge [29]. Auch die Daten von Dreher at al. zeigen eine durchschnittlich eher gute Compliance bei den beatmeten Patienten, was den Unterschied zum klassischen ARDS ebenso verdeutlicht [30]. Dieses Phänomen einer signifikanten Hypoxämie bei erhaltener Compliance der Lunge ist funktionell am ehesten durch eine ausgeprägte Ventilations-Perfusions-Verteilungsstörung zu erklären. Die virale Infektion führt in der Frühphase zu einer moderaten lokalen, subpleural gelegenen Entzündung mit interstitieller Flüssigkeitsansammlung (entspricht bildmorphologisch dem Milchglasmuster in der CT). Der überwiegende Teil der Lunge ist nicht erkrankt, was die normal erhaltene Dehnbarkeit der Lunge erklärt [31]. In den erkrankten Arealen sind die Gefäße maximal dilatiert [31-33] mit einem zu postulierenden Verlust der hypoxischen Vasokonstruktion (Euler-Liljestrand-Reflex) und damit einer Erhöhung des Shuntvolumens. Nicht geklärt ist, ob dies Folge eines Endothelschadens oder einer aktiven Relaxation der glatten Gefäßmuskulatur durch inflammatorische Mediatoren ist. Die physiologische Antwort auf die Hypoxämie ist eine Steigerung der Ventilation, was jedoch wegen der erhaltenen Compliance von den Patienten nicht als Dyspnoe empfunden wird. So erklärt sich die bei den Patienten beobachtete klinische Situation, dass trotz ausgeprägter Hypokapnie mit $\mathrm{PaCO}_{2}$-Werten unter $22 \mathrm{mmHg}$ bei gleichzeitiger signifikanter Hypoxämie der Patient keine oder nur geringe Dyspnoe empfindet.

Der führende klinische Befund ist neben der Erfassung des Gasaustausches mit der Blutgasbestimmung die Messung der Atemfrequenz sowie deren Änderung im Verlauf, die als Surrogatparameter der Atemarbeit aufgefasst werden kann. Eine Bestimmung der Atemarbeit und der intrathorakalen Druckveränderungen über eine Ösophagus-Druck Messung wäre zwar wünschenswert und hilfreich [29,34], lässt sich jedoch klinisch nicht anwenden, insbesondere weil die zur Messung des Ösophagusdruckes erforderliche Technik und Erfahrung auf den Intensivstationen nicht allgemein vorhanden sind. Die erhöhte Atemfrequenz mit Steigerung der Ventilation führt möglicherweise durch den damit verbundenen mechanischen Stress (Scherkräftebildung, hohe intrapleurale Druckamplitude) zu einer weiteren Schädigung der Lunge. Dieses Phänomen wurde erstmals von Barach et al. $1938[35,36]$ und Mascheroni et al. 1998 [3] experimentell beschrieben und als Patient-Self Inflicted Lung Injury (P-SILI) bezeichnet [38]. In dieser Phase kann bis zu einem gewissen Grad mit der Zufuhr von Sauerstoff eine ventilatorische Entlastung erreicht werden. Aufgrund eines anzunehmenden Shunts ist die Effizienz dieser Sauerstoffgabe jedoch potentiell zunehmend eingeschränkt.

Aus pathophysiologischer Sicht könnte in dieser Phase zur Verhinderung eines möglichen selbst- induzierten Lungenschadens eine mechanische Unterstützung mittels nicht-invasiver Beatmung oder CPAP über ein Maskensystem oder Helm unter- stützend sein (siehe Stellungnahme 3). Allerdings ist dies kritisch zu sehen, wenn die Unterstützung, unter Berücksichtigung der möglichst geringen mechanischen Belastung der Lunge, nicht auch zu einer Reduktion der Atemfrequenz unter 30/min führt. Eine fehlende Synchronie zwischen Patienten und dem Beatmungsgerät oder zu hohe Druckamplituden werden in der vulnerablen Gewebssituation im Lungenparenchym zu einer fortschreitenden Schädigung beitragen. Inwieweit ein solcher Stress pharmakologisch mit niedrig dosiertem Morphin reduziert werden kann, muss klinisch überprüft werden. Die Frage bleibt jedoch offen und muss individuell beurteilt werden, ob dann, bei Versagen der Sauerstofftherapie und/oder der nicht-invasiven Beatmung (bzw. CPAP), eine kontrollierte Intubation und invasive Beatmung durchgeführt werden soll, um den mechanischen Stress durch die erhöhten Atemanstrengungen zu reduzieren. Aufgrund der durch eine invasive Beatmung zu erwartenden zusätzlichen Schädigung der Lunge muss schließlich auch eine extracorporale Membranoxygenierung (ECMO) erwogen werden; diese ist sicher lungenprotektiver, weist jedoch auch eigene zusätzliche Risiken auf (siehe Stellungnahme 5).

\subsection{COVID-19-Pneumonie Typ H}

In ca. 15-20\% der stationär behandelten Patienten entwickelt sich nach den aktuellen Studien eine schwere Schädigung der Lunge. Entsprechend zeigen sich in der CT flächenhafte Konsoldierungen, wie sie auch bei anderen schweren Pneumonien und Patienten mit z. B. extrapulmonalem ARDS zu sehen sind. Auch nosokomiale Infektionen können entsprechenden Bildmustern zugrunde liegen.

Den progredienten kritischen Zustand beschreibt die Arbeitsgruppe von Gattinoni et al. als Typ H-COVID-19-Pneumonie:

- High (high elastance,d.h geringe Compliance) als Folge der Zunahme des intrapulmonalen Ödems

- Hoher (high) Rechts-Links-Shunt

- Hohes (high) Lungengewicht und hoher (high) Anteil von rekrutierbarem Lungengewebe.

Dieser Zustand reflektiert die pathophysiologischen Befunde eines schweren pneumogenen ARDS mit den pathologischen Zeichen eines diffusen Alveloarschadens [39]. Ganz ähnliche Veränderungen wurden auch bei Patienten gesehen, die an SARS [40] und MERS [41] verstorben sind.

Das Modell von Gattinoni et al. [29] erweist sich als gute Grundlage für ein besseres Verständnis der Pathophysiologie der COVID-19-Pneumonie. Gleichwohl bleiben viele Fragen offen. Aus klinischer Sicht muss gefordert werden, sowohl bei spontan atmenden Patienten als auch und gerade bei Patienten nach Intubation diesbezüglich eine umfangreiche Diagnostik durchzuführen.

Zum anderen ist die Untersuchung der kardiovaskulären Situation von entscheidender Wichtigkeit.

Die ersten Daten aus China zeigten frühzeitig zu Beginn der Pandemie einen hohem Anteil von kardial erkrankten Patienten (20 bis 30\% der hospitalisierten Patienten) - Zahlen die sich 
auch in den europäischen Patientenkollektiven bestätigten [6, 42]. Als Ausdruck der kardialen Schädigung müssen die in Studien regelmäßig beschriebenen erhöhten Werte für Troponin gewertet werden, die mit einer eingeschränkten Prognose assoziiert sind $[21,43]$. Die Analyse von verstorbenen Patienten in der Wuhan-Kohorte fand in $34 \%$ eine kardiale Schädigung bzw. eine kardiale Insuffizienz in $40 \%$, entweder als alleinige Ursache oder in Kombination mit einer respiratorischen Insuffizienz [21,44-46]. Das assoziierte Letalitätsrisiko einer akuten kardialen Schädigung war dabei höher als das Alter, ein Diabetes mellitus, eine COPD und eine vorbestehende kardiale Erkrankungen. Ursächlich müssen mehrere Faktoren diskutiert werden, auch mögliche medikament-toxische Schädigungen können nicht ausgeschlossen werden, bei einer häufig in den Studien beschriebene Einsatz verschiedenster Medikamente. Insbesondere muss auch eine schon früh mit der Entwicklung der Hypoxämie einsetzende erhöhte kardiale Belastung angenommen werden.

\subsection{Bedeutung der kardiovaskulären Belastung}

Die Hypoxämie mit Erniedrigung des Sauerstoffgehaltes erfordert eine Zunahme des Herzzeitvolumens, um den Sauerstofftransport adäquat zu sichern, da sich das Sauerstoffangebot als Produkt aus Herzzeitvolumen und Sauerstoffgehalt errechnet. Gleichzeitig kann das Herz als Folge der Hyperventilation zusätzlich durch eine Nachlasterhöhung für den linken Ventrikel belastet werden. Die erhöhte Atemanstrengung führt zu einer Verstärkung des negativen intrathorakalen Druckes, sodass der transmurale Druck für den linken Ventrikel ansteigt. Im Rahmen der Entwicklung einer Hypoxämie kann es aus pathophysiologischer Sicht zu einer Rechtsherzbelastung kommen, allerdings liegen dafür aktuell für die frühe Phase der Erkrankung keine Hinweise vor. Inwieweit es bei schweren Verläufen zu einer zunehmenden Belastung des rechten Herzens in Analogie zum schweren ARDS kommt, bedarf noch weiterer Untersuchungen.

Die systemische Entzündungsreaktion kann wie bei ambulant erworbener Pneumonie (CAP) kardiale Komplikationen wie Rhythmusstörungen, Herzinsuffizienz und Koronarereignisse begünstigen. Die Rate an kardialen Manifestationen ist jedoch höher als die Rate bei CAP (ca. 25\%).

Weitere Ursache der kardialen Schädigung kann eine Myokarditis sein. Allerdings liegen dazu bisher nur wenige aussagekräftige Kasuistiken vor.

Inwieweit die regelmäßig gefundenen erhöhten D-Dimere eine erhöhte Koagulopathie reflektieren, ist ebenfalls noch nicht geklärt. Tatsächlich scheint die Erkrankung mit einem erhöhten Risiko für thrombotische Ereignisse und Störungen des Gerinnungssystems einherzugehen. So konnte in einer Serie von 81 schwer erkrankten COVID-19Patienten bei $25 \%$ eine Lungenembolie nachgewiesen werden [47]. Allerdings ist unklar, ob es sich hierbei um thrombo-embolische Ereignisse oder in-situ Thrombosen handelt.

Kernaussage 1.1: Die COVID-19 Pneumonie kann in einem Modell pathophysiologisch in 2 Typen (L-Typ und $\mathrm{H}$-Typ) eingeteilt werden, die einer frühen und späten Phase entspre- chen. Diese Unterscheidung kann für die apparative Differenzialtherapie der ARI erwogen werden.

Kernaussage 1.2: Die kardiale Komorbidität, vorbestehend oder COVID-19 assoziiert, beeinflusst sowohl den Erkrankungsverlauf als auch die Prognose maßgeblich und soll daher in jeder Phase der Behandlung zusätzlich berücksichtigt werden.

Feststellung 1.1: Die frühe Phase entspricht keinem typischen Bild eines pneumogenen ARDS. Späte Phasen können einem pneumogenen ARDS entsprechen; differenzialdiagnostisch sind nosokomiale Infektionen sowie kardiale und thromboembolische Komplikationen zu berücksichtigen.

\section{Stellungnahme 2:}

Zeitlicher Verlauf und Prognose der akuten respiratorischen Insuffizienz im Laufe der Erkrankung (Randerath,W.; Bauer, T.)

\subsection{Einleitung}

COVID-19, die pulmonale Erkrankung, verursacht durch das SARS-CoV-2-Virus, ist eine Pneumonie, deren Verlauf in der pandemischen Situation durch die fehlende Immunität gekennzeichnet ist. Vergleichbare Erkrankungen sind Infektionen mit Rekombinanten des Grippevirus mit fehlender oder geringer Immunität in der Bevölkerung (z. B. Influenza A/H1N1) [48]. Epidemiologisch handelt es sich um eine sog. Typ-3-Pandemie mit einer hohen Zahl an infizierten Personen, aber einer vergleichsweise geringen Sterblichkeit. Weltweit versterben $6.1 \%$ der Patienten mit gesicherter Infektion (https://www.who.int/ docs/default-source/coronaviruse/situation-reports/ 20200410-sitrep-81-covid-19.pdf?sfvrsn= ca96eb84_2, Zugriff am 11.04.2020). Die Sterblichkeit wird aber zurzeit vermutlich deutlich überschätzt, da die Dunkelziffer der Infizierten hoch ist. Dafür sprechen auch die großen regionalen Unterschiede der Gesamtmortalität zwischen $0,9 \%$ in Korea und 7,2\% in Italien $[49,50]$.

In Abwesenheit einer kausalen Therapie wird die Schädigung des Organismus bei COVID-19 durch 2 Faktoren vermittelt: Erstens durch den direkten zytotoxischen Effekt durch Einschleusung, intrazelluläre Replikation, Ausschleusung und Untergang der Wirtszelle und zweitens durch das Versagen der Entwicklung einer ausreichenden Immunität zur Kontrolle der Infektion. Bei einer Typ-3-Pandemie gehen wir davon aus, dass der direkt zytotoxische Effekt nur in Ausnahmefällen einen mortalitätsvermittelnden Effekt hat, da die Sterblichkeit in der frühen Infektionsphase höher sein müsste und das Alter und Komorbiditäten eine untergeordnete Rolle spielen würden. Zhou et al. untersuchten retrospektiv 191 Patienten mit stationärer Behandlungspflichtigkeit und gesicherter COVID-19-Erkrankung, von denen 54 verstorben waren (28\%). Die häufigsten Komorbiditäten waren eine arterielle Hypertonie (30\%), ein Diabetes mellitus (19\%) und die koronare Herzkrankheit (8\%) [22]. Multivariate Analysen zeigten eine signifikant erhöhte Mortalität bei zunehmendem Alter (OR 1,10, 95\% Cl 1,03-1,17, pro Lebensjahr; $p=0.0043)$, höherem Score-Wert im Sequential Organ Failure Assessment (SOFA) (5.65, 2.61 - 12.23; p<0.0001) 
und D-Dimeren $>1 \mu \mathrm{g} / \mathrm{ml}(18,42,2,64-128,55 ; \mathrm{p}=0.0033)$. Das Virus war bei nicht-überlebenden Patienten bis zum Tod nachweisbar (bis zu 37 Tage) [22].

Im zeitlichen Verlauf trat Dyspnoe im Median nach 13 Tagen auf (Spanne 9-16,5 Tage) und war nicht unterschiedlich bei Überlebenden und Nicht-Überlebenden. Die von Siddiqi et al. vorgeschlagene Einteilung der Erkrankung in 3 Phasen erscheint somit klinisch sinnvoll [15] ( A Abb. 1).

\subsection{Phase I: Frühe Infektion}

Die Einschleusung des SARS-CoV-2 erfolgt über das Angiotensin-Converting-Enzym-2 (ACE2), das in der Schleimhaut des Rachens, der Lunge und des Dünndarms in unterschiedlicher Dichte vorhanden ist. Die klinischen Symptome sind Geschmacksstörungen, Halsschmerzen, Husten und seltener Durchfall. Für den Virusnachweis werden aktuell Abstriche aus dem Nasen-Rachenraum zur weiteren Testung mittels PCR entnommen. Neuere Daten zeigen allerdings, dass Nasenabstriche in $27 \%$ und Rachenabstriche in $68 \%$ der Fälle negativ sein können, obwohl der Patient an COVID-19 erkrankt ist [51]. Daher empfiehlt das Robert Koch Institut (RKI) bei weiterhin bestehendem Verdacht und negativen Proben des oberen Respirationstraktes auch Proben aus dem primären Replikationsort des Virus, also aus den tiefen Atemwegen, zu untersuchen. Aus klinischer Sicht wird der Beginn der Erkrankung am besten mit dem Auftreten von Fieber und/oder grippeähnlichen Symptomen festgelegt [20]. Alle 3 klinischen Verläufe (leicht, schwer und kritisch) können sich, abhängig von der Immunität und Komorbidität, aus der Phase I entwickeln.

\subsection{Phase II: Pulmonale Erkrankung}

Der Virusnachweis im Rachen ist in den ersten Tagen der Erkrankung hoch, die pulmonale Erkrankung beginnt jedoch erst mit der Replikation in der Lunge und kennzeichnet den Beginn der viralen Pneumonie [52,53]. Klinisch kommen Luftnot und Husten hinzu; eine pulmonale Verdichtung ist in der ThoraxÜbersichtsaufnahme oder im Thorax-CT als Milchglastrübung dokumentierbar [54]. Die differenzierte Schweregradeinteilung in dieser Publikation für die Phase II in die Phase Ila ohne Hypoxämie $\left(\mathrm{PaO}_{2} / \mathrm{FiO}_{2} \geq 300\right.$ entsprechend einem arteriellen oder kapillären $\mathrm{PaO}_{2}$ von $\geq 63 \mathrm{mmHg}$ bei Raumluft) und die Phase IIb mit Hypoxämie $\left(\mathrm{PaO}_{2} / \mathrm{FiO}_{2}<300\right.$ entsprechend einem arteriellen oder kapillären $\mathrm{PaO}_{2}$ von $<63 \mathrm{~mm} \mathrm{Hg}$ bei Raumluft) erscheint für die initiale Auswahl der apparativen Differenzialtherapie und des Versorgungsortes von Patienten mit COVID19 plausibel [15]. Die initiale Einschätzung der Hypoxämie unter supplementärem Sauerstoff anhand von Umrechnungstabellen ist bei nicht beatmeten Patienten unzuverlässig und nicht validiert.

Für die praktische Umsetzung der apparativen Differenzialtherapie der akuten respiratorischen Insuffizienz verweisen wir für die Phase Ila auf die Empfehlung 3 und ab Phase Ilb auf die Empfehlungen 4 und 5 dieses Manuskriptes.

Patienten mit COVID-19 in der Phase II werden überwiegend stationär behandelt, und der Verlauf der Erkrankung kann aktuell medikamentös nicht ausreichend sicher beeinflusst werden. Somit kommt der sachgerechten Behandlung der Komorbidität und der Überwachung der Organfunktionen eine entscheidende Bedeutung zu. In > Abb. 1 werden die klinischen Verläufe exemplarisch unterschieden. Folgende Parameter sollten in der Phase II regelhaft erhoben werden, um möglichst früh Hinweise auf kritische Verläufe wahrnehmen zu können (Therapieüberwachung).

\subsection{Therapieüberwachung}

Der SOFA-Score war ein signifikanter Prädiktor für Sterblichkeit in der multivariablen Analyse (höheres Alter, höherer SOFAScore, d-Dimer $>1 \mu \mathrm{g} / \mathrm{ml}$ bei Aufnahme) [22]. Im univariaten Vergleich trennten SOFA (Nicht-Überlebende versus Überlebende 4,5 [Spannweite 4-6] versus 1,0 [Spannweite 1-2]) und qSOFA (Nicht-Überlebende versus Überlebende 1,0 [Spannweite 1-1] versus 0 [Spannweite 0-2]) ähnlich gut. Der SOFA-Score beinhaltet die Einschätzung der Lunge $\left(\mathrm{PaO}_{2}\right)$ $\mathrm{FiO}_{2}$ ), des Nervensystems (Glasgow Coma Scale, GCS), des Herz-Kreislauf-Systems (Katecholamindosierung), der Leberfunktion (Bilirubin), der Gerinnung (Thrombozyten) und der Nierenfunktion (Kreatinin). Bei COVID-19 außerhalb der Intensivstation liegt in der Regel kein septisches Krankheitsbild zugrunde, sodass die Überwachung der Atemfrequenz, einer Bewusstseinstrübung, des Blutdrucks und der $\mathrm{SaO}_{2}$ ausreichend sein sollten (qSOFA) [55].

Ein Differenzialblutbild wird wegen der vermuteten Vorhersagekraft der Lymphozyten bei Aufnahme und im Verlauf empfohlen. In der Analyse von Zhou et al. kam eine Lymphozytenzahl unterhalb von $800 / \mu$ l häufiger bei Nicht-Überlebenden vor $(76 \%$ vs. $26 \%, p<0,0001$ [22]. Persistierend niedrige Lymphozyten wurden bei Nicht-Überlebenden in der Arbeit von Wang et al. häufiger beschrieben [20].

Eine myokardiale Schädigung („cardiac injury“) definiert als erhöhtes Troponin (hs TNI>28 ng/l, entsprechend dem oberen Grenzwert der 99\% Perzentile des verwendeten Testsystems) wurde bei Überlebenden weniger häufig beobachtet als bei Nicht-Überlebenden (15 vs. $28 \%$ ) [6]. In einer multivariaten Analyse mit 416 Patienten waren die myokardiale Schädigung sowie die Entwicklung eines ARDS unabhängige Risikofaktoren für ein Nicht-Überleben (Kaplan-Meier, log-rank Test) [56, 57].

\section{D-Dimere}

Störungen der Gerinnung sind bei Patienten mit schweren Infektionen im Rahmen einer Sepsis ein wichtiger Faktor für die Einschätzung der Schwere der Erkrankung [58]. Erhöhte D-Dimere und insbesondere, wenn diese im Verlauf erhöht blieben, waren in 3 retrospektiven Studien mit einer höheren Wahrscheinlichkeit des Versterbens assoziiert [20, 22, 59]. Yin et al. verglichen partielle Thromboplastinzeit (PTT), Thrombozytenzahl und D-Dimere von Patienten mit COVID-19 mit denen von Patienten mit schweren Pneumonien anderer Ätiologien. Die Autoren fanden keinen Unterschied hinsichtlich der Höhe der D-Dimere (COVID-19: $1,94 \mu \mathrm{g} / \mathrm{ml}$ [Spannweite 0,90-9,44] versus Non-COVID-19 2,25 $\mathrm{g} / \mathrm{ml}$ [Spannweite 1,40-5,81]). Jedoch waren in beiden Gruppen die absoluten Werte der DDimere in jedem Fall oberhalb des oberen Grenzwertes von $0,5 \mu \mathrm{g} / \mathrm{ml}$. Die Thrombozytenzahl war zwar bei COVID-19 Patienten etwas erhöht, allerdings durchgehend noch im Refe- 
renzbereich [60]. Ob die beobachteten Störungen der Gerinnung bei Patienten mit COVID-19 spezifisch für die Infektion mit SARS-CoV-2 sind oder im Rahmen der (beginnenden) Sepsis interpretiert werden müssen, kann aktuell nicht beantwortet werden.

Folgende weitere Laborwerte können ebenfalls auf schwere Verläufe hinweisen: Erhöhung von Leberenzymen, LDH und Kreatinin. Erhöhte Entzündungsparameter wie C-reaktives Protein (CRP), Interleukin-6 oder Ferritin waren ebenfalls prognostisch ungünstig [20].

\subsection{Phase III: Hyperinflammatorische Erkrankung}

Bei unzureichender Entwicklung einer humoralen Immunantwort und damit unzureichender Inaktivierung und Elimination von SARS-CoV-2 kommt es zu der hyperinflammatorischen Phase III mit dem gehäuften Auftreten von Organversagen und insbesondere der Möglichkeit eines weiteren Lungenschadens in Form eines ARDS. Die Entwicklung eines ARDS ist weitgehend unabhängig von dem schädigenden Agens und kann sowohl bei Pneumonien als auch Einzel- oder Mehrorganschädigungen außerhalb der Lunge vorkommen. Pathophysiologisch ist die Hyperinflammation bei COVID-19 aufgrund der fehlenden Immunantwort entscheidend [61]. Mit der aktuell gültigen Berlin-Definition des ARDS kann der Erkrankungsbeginn innerhalb einer Woche nach Auftreten von Risikofaktoren oder neuer oder zunehmender respiratorischer Symptome liegen und ist somit zeitlich für die Charakterisierung von COVID-19-Pneumonien relevant [62]. Allerdings ist die ARDS-Definition nosologisch bei COVID-19 nicht uneingeschränkt übertragbar (siehe Stellungnahme 1) und legt zusätzlich noch 3 Schweregrade zugrunde, nach denen nicht in allen Publikationen unterschieden worden ist:

- mild: $\mathrm{PaO}_{2} / \mathrm{FiO}_{2}=201-300$ mmHg mit PEEP oder $\mathrm{CPAP} \geq 5 \mathrm{cmH}_{2} \mathrm{O}$

- moderat: $\mathrm{PaO}_{2} / \mathrm{FiO}_{2}=101-200 \mathrm{mmHg}$ mit $\mathrm{PEEP} \geq 5 \mathrm{cmH}_{2} \mathrm{O}$

- schwer: $\mathrm{PaO}_{2} / \mathrm{FiO}_{2}<100 \mathrm{mmHg}$ mit $\mathrm{PEEP} \geq 5 \mathrm{cmH}_{2} \mathrm{O}$

In Zusammenhang mit COVID-19-Pneumonien ist die BerlinDefinition in den folgenden beschriebenen Publikationen nicht durchgehend durchgehalten worden, sodass ein Vergleich der klinischen Ergebnisse nur mit Einschränkungen möglich ist. Dennoch sollen sie hier zur Orientierung wiedergegeben werden.

Die zeitliche Analyse der Daten von Intensivpatienten mit COVID-19 zeigt, dass in dieser Patientengruppe die Dyspnoe im Median erst 6,5 Tagen nach Beginn erster Symptome auftrat. Allerdings entwickelte sich ein moderates bis schweres ARDS danach rasch, im Median in 2,5 Tagen nach Auftreten der Dyspnoe $[22,63,64]$. Wang et al beschrieben Charakteristika und Verlauf von 138 COVID-19 Patienten, die stationär behandelt wurden [20]. Insgesamt 26\% mussten wegen komplizierter Verläufe auf die Intensivstationen verlegt werden, davon $61 \%$ wegen eines ARDS. Der mediane $\mathrm{PaO}_{2} / \mathrm{FIO}_{2}$ lag bei $136 \mathrm{mmHg}$ (Spanne $103-234 \mathrm{~mm} \mathrm{Hg}$ ), sodass es sich hier ganz überwiegend um moderates bis schwerwiegendes ARDS gehandelt hat. Weitere Gründe waren Arrhythmien (44\%) und Schock (31\%). Die Zeitdauer von der Aufnahme bis zum mode- raten bis schwerwiegenden ARDS betrug in diesem Kollektiv im Mittel 8 Tage. Die intensivpflichtigen Patienten erhielten folgende apparative Differenzialtherapien der akuten respiratorischen Insuffizienz: High-Flow (11\%), nicht-invasive Beatmung (42\%) und invasive Beatmung (47\%) [20].

Kritisch gesehen werden muss in diesem Zusammenhang auch die Studie von Wu et al. [65], die keine Definition des ARDS oder seiner Schweregrade enthält. Die Zusammensetzung der apparativen Differenzialtherapien in der Kohorte der ARDS-Patienten $(n=84)$ in dieser Studie (High-Flow $(20 \%)$, nicht-invasive Beatmung (73\%) und invasive Beatmung \pm ECMO (7\%) suggeriert, dass es sich hier ganz überwiegend um milde Schweregrade gehandelt hat.

Ein anderes Krankengut untersuchten Yang et al. mit 52 kritisch kranken Erwachsenen in einer Kohorte von 710 Patienten mit SARS-CoV-2 Pneumonie. Nach 28 Tagen waren 32 Patienten verstorben, im Mittel 7 Tage nach Aufnahme auf der Intensivstation. Bei kritisch Kranken waren das ausgeprägte hypoxämische Atmungsversagen und ein ARDS die hervorstechenden Merkmale, während ein hyperkapnisches Versagen nur selten auftrat. Eine mechanische Beatmung war bei $42-100 \%$ nötig $[6,20,64]$.

Zu den bisher beschriebenen Risikofaktoren für die Entwicklung eines ARDS gehören Alter, Begleiterkrankungen, hohes Fieber $>39^{\circ} \mathrm{C}$, Raucheranamnese und Laborwerte (ausgeprägte Lymphozytopenie und Erhöhungen des Procalcitonin) $[63,66]$.

Nach ersten Berichten werden die Intensivaufenthalte als prolongiert und das Weaning als verzögert beschrieben. Erholungszeiten werden mit bis zu 6 Wochen angegeben. Zu den typischen Komplikationen im Verlauf des COVID-19-assoziierten ARDS gehören das akute Nierenversagen (29\%), Leberwerterhöhungen (29\%) und kardiale Schädigungen (23-33\%). Bei Letzteren sind eine Kardiomyopathie, eine Perikarditis, Herzrhythmusstörungen und der plötzliche Herztod zu nennen. Sie treten jedoch meist erst ein, wenn die pulmonalen Symptome bereits rückläufig sind $[63,64]$. Multi-Organversagen, septischer Schock (13\%) und sekundäre Pneumonien werden seltener beschrieben (12\%).

Kernaussage 2.1: Die Einschätzung des Ausmaßes der akuten respiratorischen Insuffizienz der COVID-19-Pneumonie soll durch eine arterielle oder kapilläre Blutgasanalyse bei Raumluft erfolgen und die Errechnung des Sauerstoffangebotes (bemisst sich aus den Variablen der Sauerstoffsättigung, des Hb, der Hüfner'schen Korrekturzahl sowie dem Herzminutenvolumen) beinhalten.

Kernaussage 2.2: Für die klinische Einschätzung des Verlaufs von COVID-19-Pneumonie -Patienten soll ein klinisches (z. B. qSOFA-Score) und laborchemisches Monitoring (mindestens: D-Dimere, CRP, PCT, Thrombozyten, LDH, Troponin, Ferritin und NT-Pro-BNP) zur Detektion eines multiplen Organversagens in Verbindung mit einem weiteren Parameter des respiratorischen Versagens erfolgen (z. B. $\mathrm{SaO}_{2}$ ).

Feststellung 2.1: COVID-19 verläuft in 3 zeitlich sequenzielIen Krankheitsphasen (frühe Infektion, pulmonale Erkrankung, hyperinflammatorische Erkrankung). 


\section{Stellungnahme 3:}

Sauerstoff-Insufflation, High-Flow Sauerstoff (NHF), NIV und invasive Beatmung unter besonderer Berücksichtigung der infektiösen Aerosolbildung (Geiseler, J., Dellweg, D.)

\subsection{Grundlagen Aerosolphysik und Übertragung von infektiösen Partikeln}

Das Sars-CoV-2 hat einen variablen Durchmesser, der zwischen 60 und 140 Nanometern liegt. [67]. Der hauptsächliche Übertragungsweg des Virus ist aerogen. Viren können auf Oberflächen mittels PCR nachgewiesen, nicht aber angezüchtet werden. Der Transport der Viren erfolgt mittels Aerosolen, die im Respirationstrakt infizierter Menschen entstehen [68]. Wichtig ist weiterhin, dass die Vitalität von Viren bereits im Aerosol abnimmt. Untersucht man im Experiment gleichzeitig die Menge viraler RNA und die Menge an vitalem und damit potenziell infektiösem Virus bei Influenza A, so ist bereits nach 90 Minuten - trotz gleichbleibender Menge an viraler RNA -die Anzahl vitaler und damit infektiöser Viren um den Faktor $10^{2}$ reduziert [69].

\subsection{Physikalische Eigenschaften von Aerosolen}

Für die Verbreitung von Aerosolen aus der menschlichen Lunge sind folgende Aspekte von Bedeutung: Die Entstehung, die Freisetzung, das Verhalten der Aerosole im Raum und die Deposition der Aerosole nach erneuter Inhalation durch eine andere Person.

\subsubsection{Entstehung und Freisetzung}

Die Freisetzung von Aerosolen benötigt Energie. Hierfür reicht bereits die Energie der normalen Ruheatmung [68,70-72]. Husten oder Niesen erhöht die Austrittsgeschwindigkeit, verglichen mit der Ruheatmung, etwa um den Faktor 4 [73]. Die maximale Reichweite der Aerosolwolke vor dem Gesicht unterscheidet sich dabei aber nicht wesentlich und liegt bei $0,6 \mathrm{~m}$ für normales Atmen, 0,6 m für Niesen und 0,8 m für Husten [73]. Die alleinige Betrachtung der Partikelmenge oder -masse reicht aber für die Bewertung der Infektiosität nicht aus. Hierfür ist zusätzlich die Konzentration der Viren in den Partikeln von Bedeutung. Diese kann bei akut viral erkrankten Patienten um den Faktor 32 differieren [74].

\subsubsection{Verhalten der Aerosole im Raum}

Aerosole sind feste oder flüssige schwebende Partikel in Gasen (hier Luft) mit einem Durchmesser von etwa 0,001 bis $100 \mu \mathrm{m}$. Für die wesentlichen Abscheidungsmechanismen Sedimentation und Impaktion ist der aerodynamische Durchmesser $\left(\mathrm{d}_{\mathrm{ae}}\right)$ wichtig, der sich aus dem Quotienten von Größe $\left(d_{o}\right)$ und Dichte des Partikels $(p)$ berechnet $\left(d_{a e}=d_{o} / p\right)$. Um Aerosole zu klassifizieren, wird in der Regel der mittlere mediane aerodynamische Durchmesser (MMAD) angegeben. Die Fähigkeit eines Aerosolpartikels, Viren zu transportieren, hängt aber von der Masse des Partikels ab. Dabei ist zu beachten, dass die Masse von der dritten Potenz des Durchmessers abhängt. Ein Partikel mit einem Durchmesser von $10 \mu \mathrm{m}$ hat dabei die gleiche Masse wie 1000 Partikel der Größe von $1 \mu \mathrm{m}$ [75].

Exhalierte Aerosole ändern ihre Teilchengröße in Abhängigkeit von der relativen Feuchtigkeit der Umgebung. Bei geringer Luftfeuchtigkeit schrumpfen diese Partikel, bei hoher Luftfeuchtigkeit können sie dagegen an Größe zunehmen und so ihre physikalischen Eigenschaften ändern [76].

Im freien Raum findet durch die Erdanziehungskraft eine Sedimentation der Partikel statt. Unterhalb einer Partikelgröße von 0,5 bis $1 \mu \mathrm{m}$ verhindert die Stokessche Reibungskraft der Luft eine Sedimentation. Aerosole dieser Größe bleiben somit nahezu konstant im Raum und können dann wieder inhaliert werden. Da Aerosole größerer Masse gemäß > Tab. 1 schneller absinken, wird das Risiko, auf diese Aerosole zu treffen, in der Nähe der Aerosolquelle (also dem Patienten) am größten sein. Generell stellt sich die Frage, ob auch kleinere Aerosolpartikel, die nicht sofort absinken, in der Luft von Patientenzimmern vorhanden sind, und das in einer Konzentration, die Infektionen hervorrufen können. Da diese Daten für Coronaviren nicht vorliegen, stützen sich die folgenden Aussagen hauptsächlich auf Experimente und Messungen mit Influenzaviren. Blanchere et al. konnten messen, dass in Raumluftproben $46 \%$ der Viruspartikel in Aerosolpartikeln von $>4 \mu \mathrm{m}$ vorkamen. Jedoch befanden sich $49 \%$ der Viren in Partikeln der Größe 1 bis $4 \mu \mathrm{m}$ und $4 \%$ in Partikeln $<1 \mu \mathrm{m}$. Fabian et al. fanden sogar $99 \%$ der viralen DNA in Partikeln $<5 \mu \mathrm{m}$. Somit befanden sich in beiden Untersuchungen $99 \%$ der Viren in respirablen Partikeln, die mehrere Stunden im Schwebezustand verbleiben können [77]. Bei Raumluftbeprobungen, die während der Influenza- Saison aus Gesundheitseinrichtungen aber auch Day-Care Zentren und Flugzeugkabinen genommen wurden, wurden $5,8 \times 10^{3}$ bis $3,7 \times 10^{4} \mathrm{Vi}$ ruskopien pro Kubikmeter Raumluft gefunden [78], was der zwei-bis zwanzigfachen Menge an Virus entspricht, die notwendig ist, um eine Infektion zu bekommen [79]. Das würde bedeuten, dass bei einer angenommenen Minutenventilation von 10 Litern im ungünstigsten Falle diese Schwelle bereits nach 5 Minuten erreicht wäre, im günstigsten Falle erst nach 50 Minuten. Einzubeziehen in diese Überlegung ist weiterhin die Vitalität (Überlebenszeit) des Virus in Aerosolen. Neue experimentelle Daten zum Coronavirus konnten zeigen, das Sars-CoV-2 in Aerosolen eine Überlebenshalbzeit von 1,1 Stunden hat [80]. Ob es in Patientenräumen zu einer gefährlichen Steady-State Konzen-

- Tab. 1 Das Verhältnis zwischen Sedimentation und Diffusion in Abhängigkeit vom Partikeldurchmesser [75].

\begin{tabular}{|c|c|c|}
\hline $\begin{array}{l}\text { Partikeldurch- } \\
\text { messer }(\boldsymbol{\mu m})\end{array}$ & $\begin{array}{l}\text { Sedimentation } \\
(\mu \mathrm{m} / \mathbf{s})\end{array}$ & Diffusion $(\boldsymbol{\mu m} / \mathbf{s})$ \\
\hline 0,01 & 0,07 & 340 \\
\hline 0,1 & 0,7 & 38 \\
\hline 1 & 38 & 8 \\
\hline 5 & 740 & 3 \\
\hline 10 & 2910 & 2 \\
\hline 100 & 72000 & 1 \\
\hline
\end{tabular}


tration von Viren kommen kann, hängt weiterhin von der Viruslast des Patienten (Low- oder Superspreader), dem Atemminutenvolumen, der Größe des Raumes und der Belüftung ab. Insgesamt scheint die Übertragung von Viren durch Aerosole sehr gut möglich zu sein. Mathematische Modelle gehen z. B. für die Influenza davon aus, dass etwa $50 \%$ aller Infektionsfälle auf diesem Wege entstehen [81].

Darüber hinaus beeinflussen das Quadrat des Partikeldurchmessers, die Partikeldichte und die Viskosität des Gases (hier Raumluft) die Sinkgeschwindigkeit. Partikel unter $1 \mu \mathrm{m}$ unterliegen zusätzlich dem Gesetz der Brownschen-Molekularbewegung und diffundieren im Raum.

Die Partikel halten sich somit unterschiedlich lange in der Raumluft auf, bevor sie deponieren. Ohne dass bislang bewiesen ist, dass eine erhöhte Infektionsgefahr besteht, ist für eine konsequente Belüftung des Raumes zu sorgen und das Tragen von Masken gemäß der aktuell gültigen RKI-Empfehlungen sinnvoll. Eine arbiträre Einteilung in Aerosole und Nicht-Aerosole nach ihrer Größe, so wie es von einigen Autoren vorgeschlagen wird [82], erleichtert zwar den praktischen Umgang, wird aber der Aerosolphysik im eigentlichen Sinne nicht gerecht.

\subsubsection{Deposition der Aerosole nach Inhalation}

Aerosolpartikel folgen bis zu einer Größe von etwa 3-4 $\mu \mathrm{m}$ ihrem Trägergas. Darüber hinaus führt die Massenträgheit dazu, dass bei einer Richtungsänderung des Luftstromes das Partikel bestrebt ist geradeaus zu fliegen. Trifft es dabei auf eine Oberfläche, spricht man von Impaktion. Im oberen Respirationstrakt ist dabei die Glottisregion der Bereich, in der der Inspirationsfluss die stärkste Richtungsänderung erfährt. Kleinere Partikel haben so eine höhere Wahrscheinlichkeit in die unteren Atemwege und an die alveolare Epithelzelle zu gelangen, jedoch haben auch Partikel mit einem MMADvon etwa $10 \mu \mathrm{m}$ noch eine 50 prozentige Wahrscheinlichkeit zumindest intrabronchial deponiert zu werden [83].

\subsection{Aerosol bei Therapieverfahren zur Atmungsunterstützung}

Mittels nasaler High-Flow Therapie (NHF), CPAP, NIV oder invasiver Beatmung wird dem respiratorischen System zusätzlicher Druck oder Fluss von außen zugeführt. Eine Studie zur invasiven Beatmung konnte zeigen, dass höhere EPAP Werte (hier $>5 \mathrm{~cm}$ $\mathrm{H}_{2} \mathrm{O}$ ) die Anzahl abgeatmeter Partikel erhöhen [84]. Da respirable Aerosole auf Alveolarebene entstehen, kann ein erhöhtes alveoläres Rekruitment so anscheinend vermehrt Aerosole entstehen lassen.

\subsubsection{Nicht-invasive Beatmung}

Simonds et al. konnten zeigen, dass bei Patienten mit Erkältungssymptomen, die mit einer NIV mit Leckagesystem beatmet wurden, die Anzahl der Partikel oberhalb von $3 \mu \mathrm{m}$ in einer Entfernung von $1 \mathrm{~m}$ vom Patientenkopf entfernt signifikant zunahm [82]. Im Nahbereich (20 cm vom Patientenkopf entfernt) nahmen dagegen nur Partikel der Größe oberhalb von $10 \mu \mathrm{m}$ zu, dies allerdings bei Patienten mit Erkältungssymptomatik oder vermehrter Sekretlast. Bei gesunden Probanden wurde keine erhöhte Abgabe von Partikeln jeglicher Größe gefunden.
Wurde dagegen eine Leckage-freie Maske (non-vented) mit einem Filter verwendet, nahm die Anzahl der abgegebenen Partikel bei $20 \mathrm{~cm}$ und $1 \mathrm{~m}$ bei allen Probanden eher ab, wenn auch nicht signifikant. In einem Simulationsmodell mittels rauchmarkierter Atemluft konnte gezeigt werden, dass der Luftstrom aus dem Leckagesystem einen maximalen Strömungsweg von 0,6 m [85] bzw. 0,85 m [86] zurücklegte. Bei Maskenleckagen lag die Reichweite der Leckageflüsse unterhalb von $10 \mathrm{~cm}$ [87]. Daten zur Aerosolbildung bei NIV unter Verwendung von Doppelschlauchsystemen wurden in der Literaturrecherche nicht gefunden. Da diese Systeme mit non-vented Masken arbeiten und die Exspirationsluft durch Einbau eines Viren-Filters von infektiösen Aerosolen gereinigt werden kann, ist von einem ebenso geringen Risiko der Erzeugung von potenziellen infektiösen Aerosolen auszugehen wie bei der Verwendung von Ein-Schlauch-Systemen mit non-vented Masken. Fowler et al. berechneten in einer retrospektiven Analyse bei 9 SARS Patienten ein relatives Risiko (RR) einer Infektionsübertragung von 2,33 (95\% KI 0,25 bis 21,76; $\mathrm{p}=0.5$ ) bei Mitarbeitern, die Patienten mit einer nicht-invasiven Beatmung betreuten [88]. Das Risiko war jedoch nicht signifikant erhöht, und darüber hinaus gibt die Studie keine Hinweise über die verwendeten Maskensysteme. Eine retrospektive Analyse der Virusübertragung auf Krankenhausmitarbeiter während der SARS-Epidemie im Jahre 2003 zeigte ein erhöhtes Infektionsrisiko für Mitarbeiter, die in die Anwendung der NIV involviert waren [89]. Allerdings zeigte die Studie auch, dass das alleinige Schreiben eines EKG's bei dem Patienten unabhängig vom Beatmungsstatus mit einem sogar noch stärkeren Infektionsrisiko verbunden war.

\subsubsection{Invasive Beatmung}

Vor Beginn der invasiven Beatmung steht die Intubation des Patienten. Fowler und Kollegen beschrieben während der SARSEpidemie in Canada ein relatives Infektionsrisiko von 13,3 für die Prozedur „Intubation“ [88]. Thompson et al. untersuchten den viralen RNA Gehalt von Aerosolen während verschiedener Prozeduren im Rahmen der H1N1-Epidemie in England [90]. Sie fanden eine signifikant höhere Belastung mit viraler RNA durch Partikel mit einer Größe $<7,3 \mu$ m während der Intubation der Patienten. Die Reichweite der Aerosolkontamination in einem Simulationsmodell betrug bis zu 2 Meter um den Patientenkopf herum [91]. Das Tragen einer geeigneten Schutzausrüstung ist dementsprechend absolut notwendig, zusätzlich wird in der zuletzt zitierten Arbeit eine Box über dem Kopf des Patienten zur Verhinderung der Aerosolkontamination vorgeschlagen, die allerdings den Nachteil hat, dass die Beweglichkeit der Hände dadurch eingeschränkt ist. Die odds ratio der Aerosolproduktion bei der Intubation ist dabei 2,3. Die endotracheale Absaugung eines beatmeten Patienten hatte in derselben Studie eine odds ratio von 4,11 im Hinblick auf die Produktion von mit Viren beladenen Aerosolen. Daten zur viralen Transmission bei invasiv beatmeten Patienten außerhalb von Prozeduren finden sich nicht in der Literatur. Inwieweit z. B. ein defekter oder nicht ausreichend geblockter Tubuscuff zu einer Aerosolbildung führt, ist nicht bekannt. Darüber hinaus haben nicht alle Beatmungsgeräte einen virendichten Filter im Exspirationsschenkel. Daten hierzu finden sich nicht in der Literatur. 


\subsubsection{Nasale Highflow-Therapie (NHF)}

Bei der NHF werden transnasale Flüsse von bis zu 80I/Minute erzeugt. Die Luft führt zu einer Auswaschung des Totraumes und erzeugt einen positiven Druck in den Atemwegen. Bräunlich und Kollegen konnten zeigen, dass der Auswaschungseffekt und der Druckeffekt auch noch in den kleinen Atemwegen nachzuweisen ist [92]. Der vermehrte transnasale Einstrom von Luft führt in gleichem Maße zu einem vermehrten Ausstrom von Luft aus Nase und Mund. Eine mit Rauchpartikeln dargestellte Exspirationswolke wuchs dabei von 6,5 auf $17,2 \mathrm{~cm}$, wenn der nasale Flow von 10 auf $60 \mathrm{l} / \mathrm{min}$ erhöht wurde [93]. In einer Studie von Kotoda et al. konnten mittels NHF keine infektiösen Partikel aus den mit Hefepartikeln beladenen Atemwegen einer Simulationspuppe freigesetzt werden [94]. Leung und Kollegen untersuchten die bakterielle Abscheidung in 0,4 $\mathrm{m}$ und 1,5 $\mathrm{m}$ Entfernung vom Patientenkopf bei Patienten mit bakterieller Pneumonie. Sie verglichen dabei die Anwendung von NHF und einer einfachen Sauerstoffmaske in einem Raum mit 6-12-mal Luftaustausch pro Stunde [95]. Sie fanden keinen quantitativen Unterschied in der Keimabgabe zwischen den beiden Therapieformen, wobei davon auszugehen ist, dass eine Sauerstoffmaske den Exspirationsstrom deutlich verringert. Eine aktuelle Arbeit aus China empfiehlt die Anlage von chirurgischen Masken bei Patienten, die mit NHF therapiert werden, ohne jedoch Daten in Bezug auf den hierdurch erzielten Infektionsschutz oder eine mögliche Effektivitätseinschränkung der NHF zu liefern [96].

\subsubsection{Verneblersysteme}

Simonds at al. beschrieben einen starken Anstieg der Aerosolmenge in Patientennähe nach Inhalation mit einem Düsenvernebler. Die ansonsten gut durchgeführte Studie hat hier aber einen systematischen Fehler, da auch Aerosole aus dem Vernebler mitgemessen wurden, die den Patienten gar nicht erreicht haben. Zwei retrospektive Analysen bez. des Prozedurbezogenen Risikos von Vernebler-Anwendungen wurden während der SARS-Epidemie 2003 in Canada durchgeführt [89, 97]. Beide Studien konnten kein erhöhtes Infektionsrisiko für das medizinische Personal finden, welches die Vernebler-Therapie durchführte. Hervorzuheben ist jedoch, dass eine einfache isotone Kochsalzinhalation die Abgabe von Bioaerosolen aus der Lunge für bis zu 6 Stunden um durchschnittlich $72 \%$ vermindert [98]. Ursächlich hierfür scheint die veränderte Oberflächenspannung des Flüssigkeitsfilms auf den Atemwegsepithelien zu sein.

\subsubsection{Sauerstofftherapie}

Eine Sauerstoffgabe über eine Venturi-Maske führte in der Untersuchung von Simonds et al. zu keiner erhöhten Aerosolbildung in der Nähe des Patienten [82]. Markiert man die Ausatemluft an einem künstlich atmenden Dummy mit Rauchpartikeln, so lässt sich bei einer Sauerstoffgabe von 4, 6, 8 und 10I/ min über eine Venturi-Maske die Exspirationsluft bis zu einem Abstand von 0,2; 0,22; 0,3 und 0,4 m Entfernung vom Gesicht des Dummies darstellen [86]. Im gleichen Experiment erzeugt die Applikation von 1 bzw. $5 \mathrm{IO}_{2}$ über eine Sauerstoffbrille eine Exspirationswolke mit einer Ausdehnung von 0,66 m bzw. $1 \mathrm{~m}$.
Die Manipulation an der Sauerstofftherapie zeigte sich in einer Studie als Risikofaktor für eine virale Transmission auf das medizinische Personal [97], nicht aber in einer weiteren Studie [89].

\subsubsection{Zusammenfassung}

Die Aerosolphysik zeigt, dass eine Übertragung von infektiösen, Viren-haltigen Partikeln durch Aerosole prinzipiell möglich ist. Insbesondere von Seiten des medizinischen Personals bestehen Bedenken über eine vermehrte Arbeitsbelastung am Patientenbett v. a. bei der Durchführung einer NIV und einer damit möglichen Exposition gegenüber potenziell infektiösen Aerosolen.

Die Evidenz bez. der Anwendung von Sauerstoff-Therapie, High-Flow-Therapie, CPAP-Therapie und NIV ist in ihrer Vergleichbarkeit eingeschränkt durch verschiedene Ansätze des Nachweises von Aerosolen, aber auch unterschiedliche Raumbedingungen (mit bzw. ohne regelmäßigen Luftaustausch). Wichtig für die Beurteilung der Therapie-Situation erscheint es die Aerosolproduktion von spontan atmenden und auch hustenden Patienten als Vergleich heranzuziehen - hier zeigt sich zwar durch die technischen Maßnahmen eine teilweise geringe Zunahme der Aerosol-Reichweite. Dieseist aber geringer als diejenige bei der invasiven Beatmung, die teilweise als "Schutzintubation" zum Schutz des medizinischen Personals vor infektiösen Aerosolen empfohlen wird. In dieser Situation zeigt der Vergleich mit den Daten zur Intubation und zum endotrachealem Absaugen bei letzterem ein aus Sicht der Autoren deutlich höheres Risiko einer Aerosolexposition.

Kernaussage 3.1: Offene Systeme bzw. Leckage-Systeme (sog. vented Masken) können die Abgabe von respirablen Partikeln erhöhen. Maskenleckagen spielen bei der Aerosolbildung eine eher untergeordnete Rolle. Geschlossene Systeme (sog. non-vented Masken) mit virendichten Filtern vor dem Exspirationssystem sind sicher und führen zu keiner vermehrten Aerosolbildung. Doppel-Schlauchsysteme mit virendichten Filtern im Exspirationsschlauch sind in Analogie ebenfalls sicher und führen zu keiner vermehrten Aerosolbildung.

Kernaussage 3.2: Für das Absaugen über Tubus bzw. Trachealkanüle sollen geschlossene Absaugsysteme angewendet werden. Bei invasiver Beatmung ist darauf zu achten, dass die Exspirationsluft entsprechend gefiltert wird. Fehlen entsprechende Filter im Beatmungsgerät, sollen virendichte Filter im Exspirationsschenkel eingesetzt werden.

Kernaussage 3.3: Mit persönlicher Schutzausrüstung (Augenschutz, FFP2 - bzw. FFP-3 Maske, Kittel) kann eine Inhalationstherapie, NHF-Therapie, eine CPAP-Therapie oder eine NIV nach jetzigem Kenntnisstand vom Personal ohne erhöhtes Infektionsrisiko durchgeführt werden.

Feststellung 3.1: Die endotracheale Intubation birgt ein hohes Infektionsrisiko. Prozeduren, bei denen das invasive Beatmungssystem geöffnet werden muss, sind mit einem erhöhten Infektionsrisiko verbunden.

Feststellung 3.2: Eine NHF vergrößert die exspirierte Aerosolwolke um einige Zentimeter. Eine relevant vermehrte Abgabe infektiöser Aerosole im Vergleich zum spontan at- 
menden Patienten konnte weder in vitro noch in vivo bisher nachgewiesen werden.

Feststellung 3.3: Die Anwendung eines Düsenverneblers erhöht zwar die Aerosolmenge in der Raumluft. Es gibt jedoch kein erhöhtes Infektionsrisiko durch Düsenvernebler für das medizinische Personal. Inhalation von isotoner Kochsalzlösung reduziert die Abgabe von Aerosolen aus der Lunge deutlich.

Feststellung 3.4: Die Sauerstoffgabe über Maske oder Nasensonden führt zu keiner vermehrten Aerosolbildung. Verschiedene Sauerstoffsysteme (Nasensonden, SauerstoffMasken und Venturi-Masken) können die Luft bei der Exspiration unterschiedlich ablenken, nur bei Nasensonden mit hohen Sauerstoff-Flüssen ist die bei der Ausatmung gebildete Aerosolwolke in ihrer Reichweite größer als unter Spontanatmung.

\section{Stellungnahme 4:}

Nicht-invasive Beatmung bei der akuten respiratorischen Insuffizienz (Westhoff, M; Windisch, W.; Schönhofer, B.)

\subsection{Einleitung}

Im Rahmen der COVID-19-Pandemie wiesen etwa 5 bis $6 \%$ der Patienten eine schwere Hypoxämie mit Intensivbehandlungspflichtigkeit auf, wovon viele einer invasiven oder nicht-invasiven Beatmung bedurften [9, 64]. Ursächlich für die hypoxämische respiratorische Insuffizienz ist entweder eine schwere Pneumonie oder ein sich in der Folge entwickelndes ARDS-ähnliches Bild. Die schwere Pneumonie ist definiert durch Fieber oder vermutete Atemwegsinfektion und entweder eine Atemfrequenz $>30 / \mathrm{min}$, schwere Luftnot oder eine $\mathrm{SpO}_{2}<90 \%$ bei Raumluft. Die Diagnose des ARDS orientiert sich an den bislang vorliegenden Leitlinien bzw. Empfehlungen mit entsprechender Graduierung in mildes, moderates und schweres ARDS in Abhängigkeit von $\mathrm{PaO}_{2} / \mathrm{FiO}_{2}$-Quotienten [5, 62, 99-104]. Im Folgenden werden Möglichkeiten und Grenzen der nicht-invasive Beatmung bei der akuten respiratorischen Insuffizienz erläutert. Jegliche Therapieeskalation setzt die Festlegung eines Therapiezieles im Rahmen des Patientenwillens voraus und sollte zu Beginn des Arzt-Patienten-Kontaktes erfragt und täglich überprüft werden $[3,105]$.

\subsection{Pathophysiologie}

Als ursächlich für das schwere respiratorische Versagen bei ARDS werden ein intrapulmonales Ventilations-Perfusions-Mismatch oder ein Shunt angesehen [106]. Neuere Daten zum ARDS bei COVID-19 zeigen, dass die dort zugrundeliegenden pathophysiologischen Veränderungen vielfältig sein können. So fanden Gattinoni et al. im Rahmen ihrer Untersuchungen an invasiv beatmeten Patienten, die die Berlin-Kriterien des ARDS erfüllten, dass im Gegensatz zum typischen ARDS ein sog. „atypisches ARDS“ vorliegen kann [29,34]. Dieses war bei erhaltener Lungenmechanik durch einen Verlust der Lungenperfusionsregulation und hypoxischen Vasokonstriktion gekennzeichnet. Weiterhin zeigte sich bei einzelnen Patienten, dass Verbes- serungen der Oxygenierung unter PEEP nicht immer Folge einer verbesserten Rekrutierbarkeit von Lungengewebe waren [29, 34,107]. Daraus resultierten unterschiedliche Einstellungen der Beatmungsdrücke, speziell des PEEP, und der Effektivität der Bauchlage $[29,34,107]$. Da sich die von den Autoren gemachten Aussagen jedoch allein auf invasiv beatmete Patienten beziehen, die schon eine unterschiedlich lange Dauer einer nicht-invasiven und invasiven Beatmung aufwiesen, können sie aktuell nur bedingt auf eine NIV-Therapie bei akuter respiratorischer Insuffizienz infolge COVID-19 übertragen werden.

\subsection{Indikationsstellung Algorithmus}

Therapeutisch stehen bei Vorliegen einer Hypoxämie bzw. einer respiratorischen Insuffizienz zunächst die Gabe von Sauerstoff über Nasensonde, Venturi-Maske, und nasale High-Flow-Therapie (NHF) im Vordergrund. Bei progredienter Verschlechterung des Gasaustausches und vermehrtem Sauerstoffbedarf ist die Indikation zur CPAP-Therapie bzw. Beatmung zu überprüfen. Neben der Indikationsstellung gilt es sowohl den adäquaten Zeitpunkt als auch die Form der Beatmung, sei es invasiv oder nicht-invasiv, festzulegen. Liegt eine „do not intubate“-Order (DNI) vor, ist zu klären, ob zumindest die Durchführung einer nicht-invasiven Beatmung gewünscht wird, so wie in der vorliegenden S3-Leitlinie zur nicht-invasiven Beatmung bei akuter respiratorischer Insuffizienz ausgeführt [5].

Bei gegebener Beatmungsindikation steht beim klassischen ARDS therapeutisch die Erhöhung des transpulmonalen Drucks und die Verbesserung oder Normalisierung einer pathologisch reduzierten Residualkapazität zur Verbesserung dieses gestörten Gasaustausches im Vordergrund. Durch einen hohen und konstant einwirkenden PEEP kann ein Alveolarkollaps vermieden und eine Rekrutierung von kollabierten Alveolarbezirken erzielt werden. Aufgrund von Maskenleckagen oder -intoleranzen, die eine längerfristige Aufrechterhaltung des PEEP nur bedingt ermöglichen und infolgedessen ein rasch wieder auftretendes Derecruitment und eine konsekutive Gasaustauschverschlechterungen bedingen, ist die Anwendung der NIV mit Zunahme des ARDS-Schweregrades limitiert [5, 99].

Der Einsatz der NIV beim mittelschweren und schweren ARDS führt zu einem Therapieversagen in mehr als $50 \%$. Dieses ist bei schwerem ARDS mit Mortalitätsraten von fast $50 \%$ assoziiert [ 5 , 99]. Dabei erweist sich neben der Schwere des aktuellen Krankheitsbildes (SAPS > 37) das Ausmaß der Oxygenierungsstörung als Prädiktor für das NIV-Versagen; als kritische Grenze für eine erhöhte Mortalität wird ein $\mathrm{PaO}_{2} / \mathrm{FiO}_{2}<150 \mathrm{mmHg}$ beschrieben [108].

Hohe Tidalvolumina (>9,2 bzw. $9,5 \mathrm{ml} / \mathrm{kg}$ ) unter einer NIV sind mit einer erhöhten Mortalität assoziiert [108-111]. Daraus ist zu folgern, dass auch die NIV nur dann einen positiven Einfluss auf den Outcome hat, wenn mit ihr bei einem klassischen ARDS eine lungenprotektive Beatmung mit entsprechend hohem PEEP gelingt [109]. Spontan atmende Patienten mit akuter hypoxämischer Insuffizienz weisen einen hohen Atemantrieb mit hohen Atemzugvolumina und damit potenziell schädliche transpulmonale Druckschwankungen auf [34,38]. Da unter einer NIV der Atemantrieb des Patienten erhalten ist, kann eine zusätzliche und insbesondere zu hohe inspiratorische 
Druckunterstützung im Rahmen der NIV ein erhöhtes und damit potenziell gefährlich hohes Atemzugvolumen bedingen und die Lungenschädigung aggravieren. In diesen Situationen ist die NIV nicht mehr lungenprotektiv, da es nicht gelingt, als lungenprotektiv geltende Tidalvolumina zu applizieren [112]. Diesen Zusammenhang unterstreichen auch Gattinoni et al. [34] in ihrer Studie zum atypischen ARDS bei COVID-19 und empfehlen - unter Verweis auf die Studien von Brochard et al. bei Patienten, die unter CPAP oder NIV klinische Zeichen exzessive inspiratorischer Atemanstrengungen aufweisen, die Intubation zu bevorzugen, um exzessive intrathorakale negative Drucke und einen selbst-induzierten Lungenschaden (P-SILI) zu vermeiden [38].

Ein Therapieversuch mit nicht-invasiven Therapieverfahren in Form von NIV oder primär mit CPAP und Eskalation auf eine NIV kann bei hypoxämischer respiratorischer Insuffizienz und nicht ausreichendem Ansprechen auf eine reine Sauerstoffgabe bzw. bei leichtem ARDS sowie insbesondere bei im Vordergrund stehender hyperkapnischer respiratorischer Insuffizienz (z. B. kardiale Komorbidität, COPD, Obesitas-Hypoventilation, neuromuskuläre Erkrankung) unternommen werden [5, 99]. So beinhalten die aktuellen italienischen Empfehlungen primär die Anwendung hoher CPAP-Drücke und eskalierend erst danach die NIV [113]. Andererseits wurden in der Lombardei nur $11 \%$ der Intensivpatienten mit NIV versorgt [49]. Intubationen erfolgten bei einem medianen $\mathrm{PaO}_{2} / \mathrm{FiO}_{2}$ von 160; nachfolgend bestand ein hoher PEEP-Bedarf. Ein vergleichbares Vorgehen zu CPAP/NIV wird in den NHS-Empfehlungen in Großbritannien ausgesprochen [114], allerdings mit dem wichtigen Hinweis, dass die Intubationsschwelle niedrig sein muss und bei einer klinischen Verschlechterung (steigender $\mathrm{O}_{2}$-Bedarf, stetig oder rasch sinkende $\mathrm{SaO}_{2}$ und/oder Anstieg der Atemfrequenz und Zunahme der Atemarbeit; siehe Stellungnahme 5) eine umgehende Intubation und mechanische Beatmung in Betracht zu ziehen ist. In ihrer aktuellen Übersicht zur Therapie bei ambulant erworbenen schweren respiratorischen Virusinfektionen schlussfolgern Arabi et al. analog zur bisherigen Evidenz, dass NIV bei ausgesuchten Patienten in frühen Stadien und milderen Formen des akuten hypoxämischen Atemversagens eingesetzt werden kann [115]. Gleichzeitig weisen sie aber darauf hin, dass bei Patienten ohne frühe Besserung, NIV die Intubation lediglich verzögert, aber nicht verhindert. Ähnliches ergibt sich aus den derzeit vorliegenden Publikationen zur Beatmung bei COVID-19.

Die Entwicklung vom Auftreten erster respiratorischer Symptome bis zum ARDS und zur anschließenden Intubation kann-insbesondere bei COVID-19-rasant innerhalb weniger Tage verlaufen, sodass mitunter eine rasche Entscheidung zu einer Beatmung getroffen werden muss $[20,113,116]$. Das Vorliegen einer bilateralen Pneumonie und eine progressive Verschlechterung im Verlaufs-CT-Thorax stellen prognostisch ungünstige Zeichen für eine derartige Entwicklung dar [44, 117].

Grundsätzlich ist ein engmaschiges Monitoring zur Erfassung der Kriterien für ein NIV-Versagen mit der Möglichkeit einer raschen Überleitung auf eine invasive Beatmung erforderlich $[5,49,110,113,118,119]$, sodass die Behandlung idealer- weise auf einer Intensivstation erfolgen sollte. Das Monitoring beinhaltet eine Kontrolle der Sauerstoffsättigung, der Blutgaswerte und der Tidalvolumina, aber auch des klinischen Zustands. Eine Verschlechterung der Oxygenierung mit einem $\mathrm{PaO}_{2} / \mathrm{FiO}_{2}<150$ bzw. 175 nach einer 1-stündigen NIV, Atemfrequenzen $>30 / \mathrm{min}$, ein hoher APACHE-Score sowie ein HACORScore von $>5$ sind mit einer deutlich schlechteren Prognose verbunden [120 - 123]. Daraus resultiert der in der Abb. 2 dargestellte mögliche Therapiealgorithmus. Die Entscheidungen für oder gegen die Anwendung eines jeden einzelnen Schritts sollten jedoch an die jeweilige klinische Situation, den $\mathrm{PaCO}_{2}$, die Dynamik der respiratorischen Insuffizienz und die Erfahrung angepasst werden.

\subsection{Praktische Hinweise unter dem Aspekt der Hygiene}

Sowohl bei Anwendung der NIV als auch einer-ggf. im Intervall durchgeführten - High-Flow-Therapie (NHF) besteht - in Abhängigkeit von den applizierten Beatmungsdrucken bzw. zunehmenden Flow-Werten - eine vermehrte Aerosolbildung [88, $93,101,124]$, die bei COVID-19-Infektion ein potenzielles Risiko einer Viruskontamination darstellt (siehe Stellungnahme 3). Angst des medizinischen Personals vor einer Infektion mit COVID-19 darf jedoch kein primärer Intubationsgrund sein. Daher muss der Schutz des Personals hohe Priorität haben. Deshalb sollte das NIV-Versagen frühzeitig erkannt, d.h. die Intubation regelrecht vorbereitet und durchgeführt werden. So lässt sich eine Notfallintubation vermeiden, die nachweislich mit einem schlechteren Outcome des Patienten einhergeht und gleichzeitig infolge verlängerter Reaktionszeiten und unzureichender Schutzmaßnahmen zur Gefährdung des Notfallteams durch erhöhte Viruslast führt [2].

Aus den genannten Gründen müssen bei Anwendung der NIV Leckagen auf ein Minimum reduziert werden. Deshalb sollten bei COVID-19 Nasen-Mund-Masken, Vollgesichtsmasken oder Beatmungshelme zum Einsatz kommen. Zudem müssen non-vented Masken Verwendung finden. Die bei COVID-19 eingesetzten Beatmungsgeräte sollten bevorzugt mit Doppelschlauchsystemen betrieben werden. Bei der Verwendung von Einschlauchsystemen muss zwischen dem Interface und der intendierten Leckage (whisper-swivel) bzw. dem Ausatemventil ein virendichter Filter eingesetzt werden [104, 112].

Patienten mit vorbestehender CPAP- oder NIV-Therapie bedürfen, bei Nutzung des eigenen Gerätes und einer für die Akutsituation angepassten Druckeinstellung, eines entsprechenden Masken- und Schlauchwechsels einschließlich der Zwischenschaltung eines virendichten Filters [125].

\subsection{Zusammenfassung}

Zusammenfassend werden durch die aktuell vorliegende Evidenz $[49,13,118,126,127]$ die Empfehlungen und Leitlinien $[4,5,99,101,126]$ zur Therapie der akuten respiratorischen Insuffizienz im Wesentlichen bestätigt, wonach insbesondere das mit COVID-19 einhergehende mittelschwere und schwere ARDS weiterhin keine geeignete Indikation für CPAP bzw. NIV darstellt. 


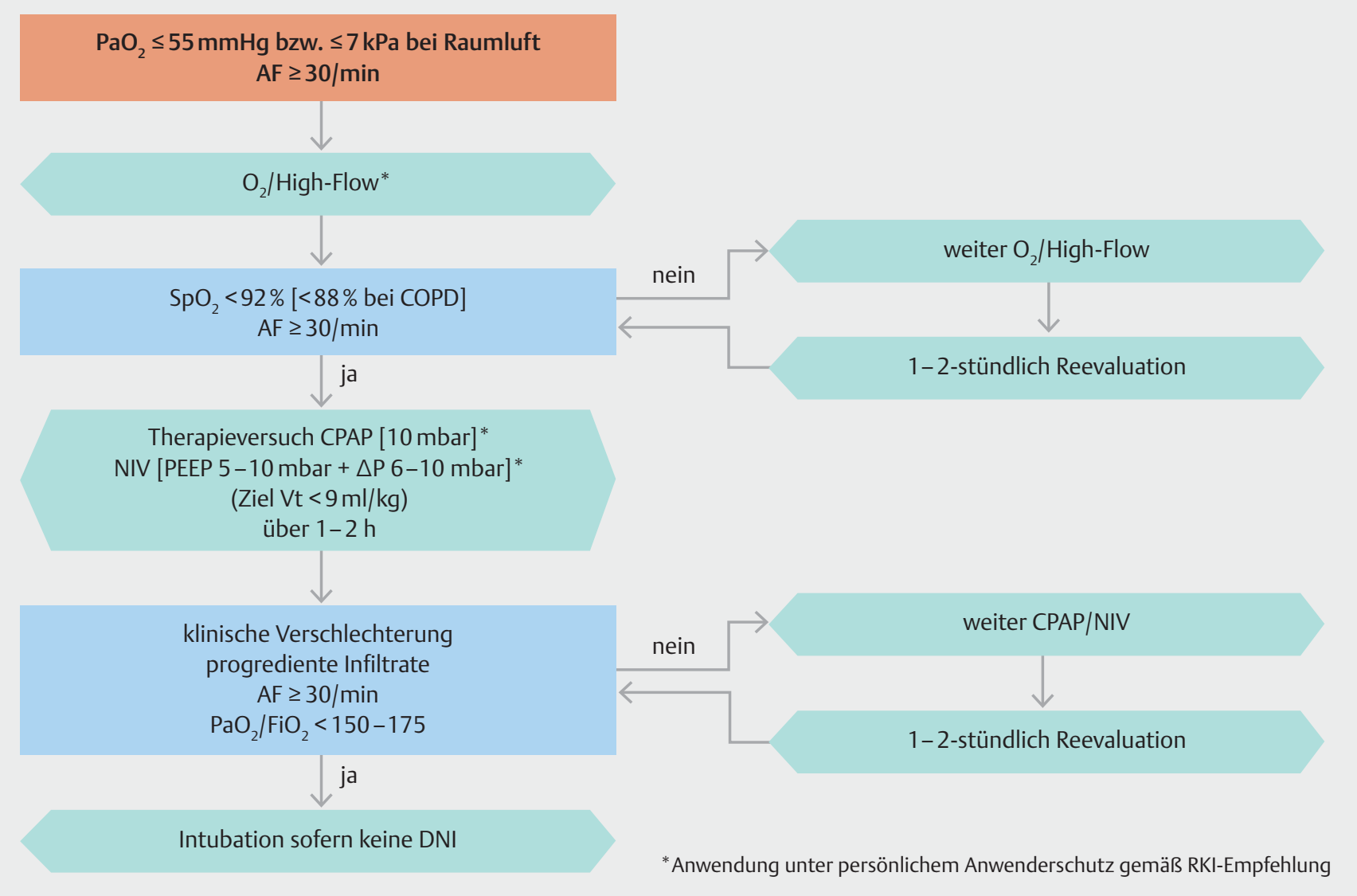

Abb.2 Mögliche apparative Therapieeskalation bei akuter respiratorischer Insuffizienz infolge COVID-19.

Kernaussage 4.1: Sauerstofftherapie inklusive High-Flow (NHF) und die nicht-invasive Beatmung/CPAP-Therapie unter Verwendung einer Mund-Nasen-Maske oder eines Beatmungshelms können als Therapieeskalation bei nicht ausreichender normaler Sauerstofftherapie durchgeführt werden, solange die Kriterien für eine endotracheale Intubation nicht erfüllt sind. In Bezug auf die Durchführung von CPAP/ NIV wird auf die gültige S3-Leitlinie verwiesen [5].

Kernaussage 4.2: Die Pathophysiologie des hypoxämischen respiratorischen Versagens ist bei COVID-19 komplex und weicht nach aktueller Vorstellung von anderen Erkrankungen mit Hypoxämie ab. Vor diesem Hintergrund kann es zu einer akuten Aggravierung der Hypoxämie sowie auch zu einer raschen Zunahme der Dyspnoe und zu einer raschen klinischen Verschlechterung unter CPAP/NIV kommen. Aus diesem Grund soll ein ständiges Monitoring unter Intubationsbereitschaft gewährleistet sein.

Kernaussage 4.3: Der Schutz des Personals durch persönliche Schutzausrüstung soll hohe Priorität haben, weil die Angst vor Ansteckung kein primärer Intubationsgrund sein darf. Aus diesem Grund sollen Leckagen auf ein Minimum reduziert werden. Geschlossene Systeme (sog. non-vented Masken) mit virendichten Filtern vor dem Exspirationssystem sind sicher und führen zu keiner vermehrten Aerosol- bildung. Doppel-Schlauchsysteme mit virendichten Filtern im Exspirationsschlauch sind in Analogie ebenfalls sicher und führen zu keiner vermehrten Aerosolbildung. Als Interface sollen non-vented Nasen-Mund-Masken, Vollgesichtsmasken oder Beatmungshelme zum Einsatz kommen. Zwischen dem Interface und der Exspirationsvorrichtung (intendierte Leckage bzw. Exspirationsventil bei Einschlauchsystemen) soll ein virendichter Filter eingesetzt werden.

\section{Stellungnahme 5:}

Versorgungskontinuum zur Behandlung der akuten respiratorischen Insuffizienz (Kluge, S., Lepper, P.M.)

\subsection{Einleitung}

Unter Berücksichtigung der in den vorigen Stellungnahmen beschriebenen Erkenntnisse soll hier eine empirisch begründete Empfehlung zur Therapie unter individualmedizinischen Aspekten erfolgen. Individualmedizinisch bedeutet, im Gegensatz zum katastrophenmedizinisch geprägten Therapieansatz, dass einzelne Individuen eine Therapie wie bei uneingeschränkt verfügbaren Ressourcen erhalten können. Dies bedeutet aber nicht, dass experimentelle Therapien unkritisch eingesetzt wer- 
den sollen und dürfen, nur weil noch nicht alle medizinischen Aspekte von COVID-19 bekannt sind. Es bedeutet auch nicht, dass nicht indizierte oder gar pathophysiologisch nicht nachvollziehbare Therapien durchgeführt werden sollen.

Der Einsatz intensivmedizinischer Behandlung muss sich an den Grundsätzen der guten klinischen Praxis orientieren. Da bislang keine kausale Therapie existiert, muss die adjuvante Therapie von Patienten mit COVID-19 daher auf die Erhaltung bzw. die Wiederherstellung der Homöostase fokussiert sein.

\subsection{Indikationen für eine Aufnahme auf die Intensivstation}

In der Notaufnahme des Krankenhauses sollen Patienten, die einer intensivierten Therapie bedürfen, rasch identifiziert werden. Hierfür soll eine Evaluation der akuten Sepsis- oder Komorbiditäts-assoziierten Organdysfunktion erfolgen. Diese Evaluation - analog zur ambulant erworbenen Pneumonie soll die Erfassung der sogenannten Minorkriterien der American Thoracic Society und der Infectious Diseases Society of America (ATS/IDSA) und individueller potenziell instabiler Komorbiditäten einschließen $[3,128]$. Patienten mit der Notwendigkeit einer maschinellen Beatmung und/oder Vasopressortherapie (Majorkriterien) sollen immer auf der Intensivstation behandelt werden. Bei Patienten mit klinisch manifester Hypoperfusion soll eine initiale Laktatbestimmung erfolgen. Eine an den initialen Schweregrad der Organdysfunktion angepasste regelmäßige Reevaluation soll bis zur klinischen Stabilität durchgeführt werden.

\section{Major-Kriterien}

1. Notwendigkeit der Intubation und maschinellen Beatmung

2. Notwendigkeit der Gabe von Vasopressoren (septischer Schock)

Für die Prädiktion von Patienten mit einem erhöhten Risiko für die Notwendigkeit einer Intensivtherapie bzw. einer maschinellen Beatmung und/oder Katecholamintherapie ohne unmittelbar erforderliche Einleitung einer Organersatztherapie (d.h. ohne Majorkriterien) wurden in den letzten Jahren mehrere Punktesysteme (Scores) entwickelt und in Studien evaluiert. Allen Scores gemeinsam ist die Identifikation klinischer, laborchemischer und radiologischer Parameter der akuten Organdysfunktion, die in unterschiedlicher Zusammensetzung verwendet, etwa ähnliche Prädiktionen erzielen. In Metaanalysen waren diese Scores dem CRB-65-Index in der Risikoprädiktion konsistent überlegen, sodass letzterer bei COVID-19 keine Anwendung findet.

Minorkriterien (Ein hohes Risiko der intensivmedizinischen Therapienotwendigkeit besteht, wenn mehr als 2 von 9 Minorkriterien vorhanden sind).

1. Schwere akute respiratorische Insuffizienz $\left(\mathrm{PaO}_{2} \leq 55 \mathrm{mmHg}\right.$ bzw. $\leq 7 \mathrm{kPa}$ bei Raumluft)

2. Atemfrequenz $\geq 30$ / Minute

3. Multilobäre Infiltrate in der Röntgen-Thoraxaufnahme

4. Neu aufgetretene Bewusstseinsstörung
5. Systemische Hypotension mit Notwendigkeit der aggressiven Volumentherapie

6. Akutes Nierenversagen (Harnstoff- $\mathrm{N} \geq 20 \mathrm{mg} / \mathrm{dL}$ )

7. Leukopenie (Leukozyten $<4000$ Zellen $/ \mathrm{mm}^{3}$ )

8. Thrombozytopenie (Thrombozyten $<100.000$ Zellen $/ \mathrm{mm}^{3}$ )

9. Hypothermie (Körpertemperatur $<36^{\circ} \mathrm{C}$ )

\subsection{Verlauf von COVID-19-Patienten im intensivmedizinischen Setting}

Ein signifikanter Anteil der respiratorisch insuffizienten Patienten präsentiert sich mit einer relevanten Hypoxie, die häufig auch durch eine hohe inspiratorische Sauerstofffraktion nicht vollständig korrigiert werden kann. Die Compliance der Lunge ist in der Mehrzahl der Fälle vergleichsweise hoch $(>50 \mathrm{~mL}$ ) $\mathrm{cmH}_{2} \mathrm{O}$ ) [34]. Diese Patienten haben, infolge der Hypoxämie, einen erheblich gesteigerten Atemantrieb und Atemminutenvolumina von>15l/min. Die Berechnung des Horovitz-Quotienten führt zumeist zu deutlich verminderten Werten, die um 120 150 liegen. Die bilateralen Veränderungen im Röntgenbild bzw. in der thorakalen CT sind oft nicht geeignet, alleine die schwere Oxygenierungsstörung der Patienten zu erklären.

Bei Messungen mittels pulmonalarteriellem Katheter finden sich nach persönlichen Messungen bei einem Teil der Patienten zunächst normale pulmonal-arterielle Drucke und normale bis erniedrigte pulmonal-vaskuläre Widerstände bei normalem oder moderat gesteigertem Herzzeitvolumen (in der Größenordnung von 6-9l/min). Eine Erklärung der Oxygenierungsstörung dürfte somit ein relevanter Rechts-Links Shunt bei eingeschränkter pulmonal-vaskulärer Autoregulation (eingeschränkte oder fehlende „hypoxisch-pulmonale Vasokonstriktion“) und einer schweren Verteilungsstörung sein (siehe Empfehlung 1). Bei diesen Patienten sollte zunächst eine Korrektur der Hypoxämie z.B. mittels nasaler High-Flow Therapie (NHF) nasalem Sauerstoff erfolgen, auch eine nicht-invasive Ventilation (NIV) kann diese Patienten stabilisieren.

\subsubsection{Einsatzort der nicht-invasiven Beatmung}

Bezugnehmend auf die aktuelle S3-Leitlinie „Nichtinvasive Beatmung als Therapie der akuten respiratorischen Insuffizienz“ sollte folgendes beachtet werden [5].

Durch die nicht-invasive Beatmung kann bei schwerer ambulant erworbener Pneumonie die Oxygenierung bei den meisten Patienten verbessert werden, allerdings ist die Versagerquote relativ hoch $[20,64]$.

Dabei erweist sich neben der Schwere des aktuellen Krankheitsbildes das Ausmaß der Oxygenierungsstörung als Prädiktor für das NIV-Versagen. Insgesamt ist ein Therapieversuch mit NIV bei schweren Formen von COVID-19, insbesondere bei Patienten mit COPD - unter Beachtung der Kontraindikationen und Abbruchkriterien-gerechtfertigt. Grundsätzlich ist ein engmaschiges Monitoring zur Erfassung der Kriterien für ein NIV-Versagen mit der Möglichkeit einer raschen Überleitung auf eine invasive Beatmung erforderlich [5], sodass die Behandlung idealerweise auf einer Intensivstation erfolgen sollte. Wichtige Argumente für die Intensivstation als Ort des Einsatzes der NIV als Alternative zur invasiven Beatmung sind die kontinuierliche Überwachung des Patienten (Monitoring) und die 
Möglichkeit des unverzögerten Beginns vital indizierter therapeutischer Maßnahmen. Die NIV stellt hinsichtlich der Qualifikation des ärztlichen und pflegerischen Personals gleich hohe Ansprüche an das Personal wie eine invasive Beatmung, sodass eine geeignete Strukturvoraussetzung gegeben sein muss.

Ausnahmen sind Patienten, die an einer ventilatorischen Insuffizienz, z.B. im Rahmen einer akuten Exazerbation der COPD, leiden. Hier kann die Beatmung im Einzelfall auch auf einer auf Beatmung spezialisierten intermediären Intensivstation durchgeführt werden. Bei Patienten mit bereits bestehender NIV ist der Übergang zwischen einer klinisch stabilen chronisch ventilatorischen Insuffizienz und einer beginnenden Dekompensation oft fließend. Hier kann bei gegebener fachlicher und struktureller Voraussetzung vereinzelt die NIV auch auf der Normalstation durchgeführt werden.

\subsubsection{Beurteilung des klinischen Verlaufes und Management auf der Intensivstation}

Die Beurteilung des Patienten sollte sich an physiologischen Zielparametern orientieren (Rekapillarisierungszeit, Laktat, Diurese, Normalisierung der Atemfrequenz) statt an numerischen Zielparametern, um ein suffizientes Sauerstoffangebot abzuschätzen zu können. Sollte der Patient einen zentralvenösen Zugang oder Pulmonaliskatheter haben, ist die Bestimmung der zentral- bzw. gemischt-venösen Sättigung hilfreich.

Eine Verschlechterung des Oxygenierung mit einem $\mathrm{PaO}_{2} /$ $\mathrm{FiO}_{2}<150$ bzw. 175 nach einer 1-stündigen NIV, Atemfrequenzen $>30 /$ min, ein hoher APACHE-Score sowie ein HACOR-Score von $>5$ stellen eine Indikation zur endotrachealen Intubation bei bestehendem kurativem Therapieziel dar [120 - 123].

Bei Patienten, die bereits intubiert und beatmet sind, gehen Bauchlage und hoher PEEP mit unterschiedlichen Erfolgsraten einher. Diese Patienten sollten gemäß der Empfehlung der S3Leitlinie beatmet werden [4]. Aufgrund des günstigen RisikoNutzen-Verhältnisses sollte jedoch der Versuch gemacht werden, Patienten durch diese Maßnahmen zu verbessern. Hohe PEEP-Werte bergen bei diesen Patienten auch dann das Risiko eines akuten Cor pulmonale, wenn eine Lungenembolie ausge- schlossen werden kann. Bei guten Compliance sind Rekrutierungsmanöver oft nicht erfolgversprechend. Der Sedierungsbedarf kann in dieser Phase der Erkrankung hoch sein. Das Volumenmanagement sollte restriktiv erfolgen, wobei berücksichtigt werden sollte, dass die Patienten durch hohes Atemminutenvolumen und Fieber überproportionale Flüssigkeitsverluste haben.

Im Verlauf der Erkrankung, die teilweise über Wochen gehen kann, nimmt die Compliance häufig ab, und die pulmonale Situation entspricht dann zunehmend einem COVID-19-Pneumonie Typ $\mathrm{H}[4,34]$.

Bei Patienten mit COVID-19 und respiratorischer Insuffizienz, bei denen eine invasive Beatmung unter Ausschöpfung der o.g. Maßnahmen nicht ausreicht, um eine ausreichende Sauerstoffaufnahme und $\mathrm{CO}_{2}$-Abgabe zu gewährleisten, soll ein extrakorporales Lungenersatzverfahren erwogen werden. Voraussetzungen sind dafür die medizinische Indikation und der Patientenwille. Für das weitere Management verweisen wir auf die gültige S3-Leitlinie zur invasiven Beatmung und zum Einsatz extrakorporaler Verfahren bei akuter respiratorischer Insuffizienz [4].

Daten über den Ausgang der verschiedenen apparativen Verfahren sind schwer zu vergleichen, da genaue Einstellungen und Parameter nicht rapportiert wurden. Die $>$ Tab. 2 gibt einen Überblick zu den Auswertungen aus China und Großbritannien. Ob diese Zahlen auch für Deutschland repräsentativ sind, kann zum jetzigen Zeitpunkt nicht eingeschätzt werde, da konkrete Zahlen aktuell noch nicht vorliegen. Einen Überblick über die apparative Differenzialtherapie der akuten respiratorischen Insuffizienz zeigt die Heterogenität der Erkrankung bei schweren Verläufen ( $\triangleright$ Tab. 2).

Kernaussage 5.1: Die nicht-invasive Beatmung bei akuter hypoxämischer Insuffizienz bei Patienten mit COVID-19 sollte auf der Intensivstation oder in einer vergleichbaren Struktur mit entsprechender personeller Expertise erfolgen.

- Tab.2 Überblick über die apparative Differenzialtherapie der akuten respiratorischen Insuffizienz bei schweren Verläufen aus der bisherigen Literatur.

\begin{tabular}{|c|c|c|c|c|c|}
\hline Studie & $\begin{array}{l}\text { Kritisch Kranke } \\
\text { N (\%) }\end{array}$ & HFNC & NIV & MV (verstorben) & ECMO \\
\hline \multicolumn{6}{|l|}{ China } \\
\hline Zhou, Lancet 2020 [22] & 50 & $41(33,81 \%)$ & $26(24,92 \%)$ & $32(31,97 \%)$ & $3(3)$ \\
\hline Wu, JAMA 2020 [65] & 84 & NR & NR & $\begin{array}{l}67(44,66 \%) \\
9 \text { noch } \\
\text { hospitalisiert }\end{array}$ & NR \\
\hline Wang, AJRCCM 2020 [127] & 344 & $35(28,80 \%)$ & $34(27,79 \%)$ & $100(97,97 \%)$ & NR \\
\hline \multicolumn{6}{|l|}{ Großbritannien } \\
\hline ICNARC 17.4.2020 & 2016 & \multicolumn{2}{|c|}{ zusammen $821(160,20 \%)$} & $1795(1209,67 \%)$ & NR \\
\hline
\end{tabular}


Kernaussage 5.2: In Bezug auf die Durchführung der invasiven Beatmung wird auf die gültige S3-Leitlinie verwiesen [4].

Kernaussage 5.3: Bei Patienten mit COVID-19 und respiratorischer Insuffizienz, bei denen eine invasive Beatmung unter Ausschöpfung der o.g. Maßnahmen nicht ausreicht, um eine ausreichende Sauerstoffaufnahme und $\mathrm{CO}_{2}$-Abgabe zu gewährleisten, soll ein extrakorporales Lungenersatzverfahren erwogen werden. Voraussetzungen sind dafür die medizinische Indikation und der Patientenwille.

Feststellung 5.1: Patienten mit COVID-19 und akuter respiratorischer Insuffizienz zeigen ein auch im intensivmedizinischen Verlauf heterogenes Erscheinungsbild und lassen sich nicht uniform in eine Kategorie des ARDS nach der Berlin-Definition einordnen.

\section{Beiträge der Autoren}

Alle Autoren haben gleichwertig zum Gesamtmanuskript beigetragen. Die Autoren haben unterschiedlich zu den einzelnen Stellungnahmen beigetragen (Stellungnahme 1 [SE, MP, TV], Stellungnahme 2 [WR, TB] Stellungnahme 3 [JG, DD], Stellungnahme 4 [MW, WW, BS], Stellungnahme 5 [SK, PL]). TB führte den Konsensusprozess und editierte das Gesamtmanuskript.

\section{Danksagung}

Wir danken Prof. Tom Schaberg und Frau Prof. Inge HansenSchaberg für die inhaltliche und formale Durchsicht des Manuskriptes.

\section{Interessenkonflikt}

Die Autorinnen/Autoren geben an, dass kein Interessenkonflikt besteht.

Literatur

[1] An der Heiden M, Buchholz U. Modelierung von Beispielszenarien der SARS-CoV-2 Epidemie 2020 in Deutschland. 2020: doi:10.25646/ 6571.2

[2] Kluge $S$, Janssens $U$, Welte $T$ et al. Empfehlungen zur intensivmedizinischen Therapie von Patienten mit COVID-19. Med Klin Intensivmed Notfmed 2020; 115: 175-177

[3] Ewig S, Hoffken G, Kern WV et al. Behandlung von erwachsenen Patienten mit ambulant erworbener Pneumonie und Pravention - Update 2016. Pneumologie 2016; 70: 151-200

[4] Fichtner F, Moerer O, Laudi S et al. Mechanical Ventilation and Extracorporeal Membrane Oxygena tion in Acute Respiratory Insufficiency. Dtsch Arztebl Int 2018; 115: 840-847

[5] Westhoff M, Schönhofer B, Neumann P et al. S3 Leitlinien: Nicht-invasive Beatmung als Therapie der akuten respiratorischen Insuffizienz. Pneumologie 2015; 69: 719-756

[6] Huang C, Wang Y, Li X et al. Clinical features of patients infected with 2019 novel coronavirus in Wuhan, China. Lancet 2020; 395: 497-506

[7] Zhu N, Zhang D, Wang W et al. A Novel Coronavirus from Patients with Pneumonia in China, 2019. N Engl J Med 2020; 382: 727-733
[8] Chen N, Zhou M, Dong X et al. Epidemiological and clinical characteristics of 99 cases of 2019 novel coronavirus pneumonia in Wuhan, China: a descriptive study. Lancet 2020; 395: 507-513

[9] Wu Z, McGoogan JM. Characteristics of and Important Lessons From the Coronavirus Disease 2019 (COVID-19) Outbreak in China: Summary of a Report of 72314 Cases From the Chinese Center for Disease Control and Prevention. Jama 2020: doi:10.1001/jama.2020.2648

[10] South AM, Diz DI, Chappell MC. COVID-19, ACE2, and the cardiovascular consequences. Am J Physiol Heart Circ Physiol 2020; 318 : H1084-H1090

[11] Zheng YY, Ma YT, Zhang JY et al. COVID-19 and the cardiovascular system. Nat Rev Cardiol 2020: doi:10.1038/s41569-020-0360-5

[12] Cheung KS, Hung IF, Chan PP et al. Gastrointestinal Manifestations of SARS-CoV-2 Infection and Virus Load in Fecal Samples from the Hong Kong Cohort and Systematic Review and Meta-analysis. Gastroenterology 2020: doi:10.1053/j.gastro.2020.03.065

[13] Lin L, Jiang X, Zhang Z et al. Gastrointestinal symptoms of 95 cases with SARS-CoV-2 infection. Gut 2020: doi:10.1136/gutjnl-2020321013

[14] Channappanavar R, Perlman S. Pathogenic human coronavirus infections: causes and consequences of cytokine storm and immunopathology. Semin Immunopathol 2017; 39: 529-539

[15] Siddiqi HK, Mehra MR. COVID-19 Illness in Native and Immunosuppressed States: A Clinical-Therapeutic Staging Proposal. The Journal of Heart and Lung Transplantation 2020: doi:10.1016/j.healun.2020.03.012

[16] Peiris JS, Chu CM, Cheng VC et al. Clinical progression and viral load in a community outbreak of coronavirus-associated SARS pneumonia: a prospective study. Lancet 2003; 361: 1767-1772

[17] Yang X, Yu Y, Xu J et al. Clinical course and outcomes of critically ill patients with SARS-CoV-2 pneumonia in Wuhan, China: a single-centered, retrospective, observational study. The Lancet Respiratory Medicine 2020: doi:10.1016/S2213-2600(20)30079-5

[18] Tetro JA. Is COVID-19 receiving ADE from other coronaviruses? Microbes Infect 2020; 22: 72-73

[19] Tilocca B, Soggiu A, Musella V et al. Molecular basis of COVID-19 relationships in different species: a one health perspective. Microbes Infect 2020: doi:10.1016/j.micinf.2020.03.002

[20] Wang D, Hu B, Hu C et al. Clinical Characteristics of 138 Hospitalized Patients With 2019 Novel Coronavirus-Infected Pneumonia in Wuhan, China. Jama 2020: doi:10.1001/jama.2020.1585

[21] Ruan Q, Yang K, Wang W et al. Clinical predictors of mortality due to COVID-19 based on an analysis of data of 150 patients from Wuhan, China. Intensive Care Med 2020: doi:10.1007/s00134-020-05991-x

[22] Zhou F, Yu T, Du R et al. Clinical course and risk factors for mortality of adult inpatients with COVID-19 in Wuhan, China: a retrospective cohort study. Lancet 2020; 395: 1054-1062

[23] Gu J, Gong E, Zhang B et al. Multiple organ infection and the pathogenesis of SARS. J Exp Med 2005; 202: 415-424

[24] Ai T, Yang Z, Hou H et al. Correlation of Chest CT and RT-PCR Testing in Coronavirus Disease 2019 (COVID-19) in China: A Report of 1014 Cases. Radiology 2020: doi:10.1148/radiol.2020200642: 200642

[25] Fang Y, Zhang H, Xu Y et al. CT Manifestations of Two Cases of 2019 Novel Coronavirus (2019-nCoV) Pneumonia. Radiology 2020; 295: 208-209

[26] Duan YN, Qin J. Pre- and Posttreatment Chest CT Findings: 2019 Novel Coronavirus (2019-nCoV) Pneumonia. Radiology 2020; 295: 21

[27] Bai HX, Hsieh B, Xiong Z et al. Performance of radiologists in differentiating COVID-19 from viral pneumonia on chest CT. Radiology 2020: doi:10.1148/radiol.2020200823: 200823

[28] Maiolo G, Collino F, Vasques F et al. Reclassifying Acute Respiratory Distress Syndrome. Am J Respir Crit Care Med 2018; 197: 1586-1595 
[29] Gattinoni L, Chiumello D, Caironi P et al. COVID-19 pneumonia: different respiratory treatments for different phenotypes? Intensive Care Med 2020: doi:10.1007/s00134-020-06033-2

[30] Dreher M, Kersten A, Bickenbach J et al. Charakteristik von 50 hospitalisierten COVID-19-Patienten mit und ohne ARDS. Dtsch Arztebl International 2020; 117: 271-278

[31] Han R, Huang L, Jiang $\mathrm{H}$ et al. Early Clinical and CT Manifestations of Coronavirus Disease 2019 (COVID-19) Pneumonia. AJR Am J Roentgenol 2020: 1-6 doi:10.2214/AJR.20.22961

[32] Zhao W, Zhong Z, Xie X et al. Relation Between Chest CT Findings and Clinical Conditions of Coronavirus Disease (COVID-19) Pneumonia: A Multicenter Study. AJR Am J Roentgenol 2020: 1-6 doi:10.2214/ AJR.20.22976

[33] Li Y, Xia L. Coronavirus Disease 2019 (COVID-19): Role of Chest CT in Diagnosis and Management. AJR Am J Roentgenol 2020: 1-7 doi:10.2214/AJR.20.22954

[34] Gattinoni L, Coppola S, Cressoni M et al. Covid-19 Does Not Lead to a "Typical" Acute Respiratory Distress Syndrome. Am J Respir Crit Care Med 2020: doi:10.1164/rccm.202003-0817LE

[35] Barach A, Martin J, Eckman M. Positive Pressure Respiration And Its Application To The Treatment Of Acute Pulmonary Edema. Annals of Internal Medicine 1938; 12: 754-759

[36] Barach AL, Eckman M et al. Studies on positive pressure respiration; general aspects and types of pressure breathing; effects on respiration and circulation at sea level. J Aviat Med 1946; 17: 290-232

[37] Mascheroni D, Kolobow T, Fumagalli R et al. Acute respiratory failure following pharmacologically induced hyperventilation: an experimental animal study. Intensive Care Med 1988; 15: 8-14

[38] Brochard L, Slutsky A, Pesenti A. Mechanical Ventilation to Minimize Progression of Lung Injury in Acute Respiratory Failure. Am J Respir Crit Care Med 2017; 195: 438-442

[39] Xu Z, Shi L, Wang Y et al. Pathological findings of COVID-19 associated with acute respiratory distress syndrome. Lancet Respir Med 2020; 8: 420-422

[40] Ding $\mathrm{Y}$, Wang $\mathrm{H}$, Shen $\mathrm{H}$ et al. The clinical pathology of severe acute respiratory syndrome (SARS): a report from China. J Pathol 2003; 200: 282-289

[41] Ng DL, Al Hosani F, Keating MK et al. Clinicopathologic, Immunohistochemical, and Ultrastructural Findings of a Fatal Case of Middle East Respiratory Syndrome Coronavirus Infection in the United Arab Emirates, April 2014. Am J Pathol 2016; 186: 652-658

[42] Grasselli G, Pesenti A, Cecconi M. Critical Care Utilization for the COVID-19 Outbreak in Lombardy, Italy: Early Experience and Forecast During an Emergency Response. JAMA 2020: doi:10.1001/jama.2020.4031

[43] Zhou F, Yu T, Du R et al. Clinical course and risk factors for mortality of adult inpatients with COVID-19 in Wuhan, China: a retrospective cohort study. The Lancet 2020: doi:10.1016/S0140-6736(20)30566-3

[44] Shi $H$, Han $X$, Jiang $N$ et al. Radiological findings from 81 patients with COVID-19 pneumonia in Wuhan, China: a descriptive study. Lancet Infect Dis 2020: doi:10.1016/s1473-3099(20)30086-4

[45] Guo T, Fan Y, Chen M et al. Cardiovascular Implications of Fatal Outcomes of Patients With Coronavirus Disease 2019 (COVID-19). JAMA cardiology 2020: doi:10.1001/jamacardio.2020.1017

[46] Gao C, Wang Y, Gu X et al. Association Between Cardiac Injury and Mortality in Hospitalized Patients Infected With Avian Influenza A (H7N9) Virus. Crit Care Med 2020; 48: 451-458

[47] Cui S, Chen S, Li X et al. Prevalence of venous thromboembolism in patients with severe novel coronavirus pneumonia. J Thromb Haemost 2020: doi: $10.1111 /$ jth. 14830

[48] Schaberg T, Bauer T, Dalhoff K et al. Management der Influenza A/ H1N1 - Pandemie im Krankenhaus: Update Januar 2010. Eine Stel- lungnahme der Deutschen Gesellschaft für Pneumologie und Beatmungsmedizin. Pneumologie 2010; 64: 124-129

[49] Grasselli G, Zangrillo A, Zanella A et al. Baseline Characteristics and Outcomes of 1591 Patients Infected With SARS-CoV-2 Admitted to ICUs of the Lombardy Region, Italy. JAMA 2020: doi:10.1001/jama.2020.5394

[50] Onder G, Rezza G, Brusaferro S. Case-Fatality Rate and Characteristics of Patients Dying in Relation to COVID-19 in Italy. Jama 2020: doi:10.1001/jama.2020.4683

[51] Wang W, Xu Y, Gao R et al. Detection of SARS-CoV-2 in Different Types of Clinical Specimens. Jama 2020: doi:10.1001/jama.2020.3786

[52] Pan Y, Zhang D, Yang P et al. Viral load of SARS-CoV-2 in clinical samples. Lancet Infect Dis 2020; 20: 411-412

[53] Zou L, Ruan F, Huang M et al. SARS-CoV-2 Viral Load in Upper Respiratory Specimens of Infected Patients. N Engl J Med 2020; 382: 1177 1179

[54] Fang Y, Zhang H, Xie J et al. Sensitivity of Chest CT for COVID-19: Comparison to RT-PCR. Radiology 2020: doi:10.1148/radiol.2020200432

[55] Jiang J, Yang J, Jin Y et al. Role of qSOFA in predicting mortality of pneumonia: A systematic review and meta-analysis. Medicine (Baltimore) 2018; 97: e12634

[56] Shi S, Qin M, Shen B et al. Association of Cardiac Injury With Mortality in Hospitalized Patients With COVID-19 in Wuhan, China. JAMA cardiology 2020: doi:10.1001/jamacardio.2020.0950

[57] Madjid M, Safavi-Naeini P, Solomon SD et al. Potential Effects of Coronaviruses on the Cardiovascular System: A Review. JAMA cardiology 2020: doi:10.1001/jamacardio.2020.1286

[58] Seymour CW, Liu VX, Iwashyna T] et al. Assessment of Clinical Criteria for Sepsis: For the Third International Consensus Definitions for Sepsis and Septic Shock (Sepsis-3). JAMA 2016; 315: 762-774

[59] Tang N, Li D, Wang X et al. Abnormal coagulation parameters are associated with poor prognosis in patients with novel coronavirus pneumonia. J Thromb Haemost 2020; 18: 844-847

[60] Yin S, Huang M, Li D et al. Difference of coagulation features between severe pneumonia induced by SARS-CoV2 and non-SARS-CoV2. J Thromb Thrombolysis 2020: doi:10.1007/s11239-020-02105-8

[61] Dembinski R, Mielck F. ARDS - Ein Update - Teil 1: Epidemiologie, Pathophysiologie und Diagnostik. Anasthesiol Intensivmed Notfallmed Schmerzther 2018; 53: 102-111

[62] Force ADT, Ranieri VM, Rubenfeld GD et al. Acute respiratory distress syndrome: the Berlin Definition. JAMA 2012; 307: 2526-2533

[63] Arentz M, Yim E, Klaff L et al. Characteristics and Outcomes of 21 Critically III Patients With COVID-19 in Washington State. Jama 2020: doi:10.1001/jama.2020.4326

[64] Yang X, Yu Y, Xu J et al. Clinical course and outcomes of critically ill patients with SARS-CoV-2 pneumonia in Wuhan, China: a single-centered, retrospective, observational study. Lancet Respir Med 2020: doi:10.1016/s2213-2600(20)30079-5

[65] Wu C, Chen X, Cai Y et al. Risk Factors Associated With Acute Respiratory Distress Syndrome and Death in Patients With Coronavirus Disease 2019 Pneumonia in Wuhan, China. JAMA internal medicine 2020: doi:10.1001/jamainternmed.2020.0994

[66] Team CC-R. Severe Outcomes Among Patients with Coronavirus Disease 2019 (COVID-19) - United States, February 12-March 16, 2020. MMWR Morbidity and mortality weekly report 2020; 69: 343-346

[67] Zhu N, Zhang D, Wang W et al. A Novel Coronavirus from Patients with Pneumonia in China, 2019. N Engl J Med 2020; 382: 727-733

[68] Papineni RS, Rosenthal FS. The size distribution of droplets in the exhaled breath of healthy human subjects. J Aerosol Med 1997; 10: 105-116 
[69] Brown JR, Tang JW, Pankhurst L et al. Influenza virus survival in aerosols and estimates of viable virus loss resulting from aerosolization and air-sampling. J Hosp Infect 2015; 91: 278-281

[70] Yan J, Grantham M, Pantelic ] et al. Infectious virus in exhaled breath of symptomatic seasonal influenza cases from a college community. Proc Natl Acad Sci U S A 2018; 115: 1081-1086

[71] Leung NHL, Chu DKW, Shiu EYC et al. Respiratory virus shedding in exhaled breath and efficacy of face masks. Nature Medicine 2020: doi:10.1038/s41591-020-0843-2

[72] Fabian P, McDevitt J], DeHaan WH et al. Influenza virus in human exhaled breath: an observational study. PLoS One 2008; 3: e2691

[73] Tang JW, Nicolle AD, Klettner CA et al. Airflow dynamics of human jets: sneezing and breathing - potential sources of infectious aerosols. PLoS One 2013; 8: e59970

[74] Bischoff WE, Swett $K$, Leng I et al. Exposure to influenza virus aerosols during routine patient care. J Infect Dis 2013; 207: 1037-1046

[75] Köhler D, Fleischer W. Inhalationstherapie. München: Arcis Verlag; 2000

[76] Wang B, Zhang A, Sun JL et al. Study of SARS transmission via liquid droplets in air. J Biomech Eng 2005; 127: 32-38

[77] Blachere FM, Lindsley WG, Pearce TA et al. Measurement of airborne influenza virus in a hospital emergency department. Clin Infect Dis 2009; 48: 438-440

[78] Yang W, Elankumaran S, Marr LC. Concentrations and size distributions of airborne influenza $A$ viruses measured indoors at a health centre, a day-care centre and on aeroplanes. J R Soc Interface 2011; 8 : $1176-1184$

[79] Alford RH, Kasel JA, Gerone PJ et al. Human influenza resulting from aerosol inhalation. Proc Soc Exp Biol Med 1966; 122: 800-804

[80] van Doremalen N, Bushmaker T, Morris DH et al. Aerosol and Surface Stability of SARS-CoV-2 as Compared with SARS-CoV-1. N Engl J Med 2020: doi:10.1056/NEJMc2004973

[81] Cowling BJ, Ip DK, Fang VJ et al. Aerosol transmission is an important mode of influenza A virus spread. Nature communications 2013; 4: 1935

[82] Simonds AK, Hanak A, Chatwin M et al. Evaluation of droplet dispersion during non-invasive ventilation, oxygen therapy, nebuliser treatment and chest physiotherapy in clinical practice: implications for management of pandemic influenza and other airborne infections. Health Technol Assess 2010; 14: 131-172

[83] Köhler D, Simonides R, Rothfuss J et al. Aerosolverteilungsmuster von 16 handelsublichen Inhalationsgeraten. Prax Klin Pneumol 1983; 37 : (Suppl. 01): 922-924

[84] Wan GH, Wu CL, Chen YF et al. Particle size concentration distribution and influences on exhaled breath particles in mechanically ventilated patients. PLoS One 2014; 9: e87088

[85] Munsiff SS, Li J, Cook SV et al. Trends in Drug-Resistant Mycobacterium tuberculosis in New York City, 1991-2003. Clinical Infectious Diseases 2006; 42: 1702-1710

[86] Hui DS, Chow BK, Ng SS et al. Exhaled air dispersion distances during noninvasive ventilation via different Respironics face masks. Chest 2009; 136: 998-1005

[87] Hui DS, Hall SD, Chan MT et al. Noninvasive positive-pressure ventilation: An experimental model to assess air and particle dispersion. Chest 2006; 130: 730-740

[88] Fowler RA, Guest CB, Lapinsky SE et al. Transmission of severe acute respiratory syndrome during intubation and mechanical ventilation. Am J Respir Crit Care Med 2004; 169: 1198-1202

[89] Raboud J, Shigayeva A, McGeer A et al. Risk factors for SARS transmission from patients requiring intubation: a multicentre investigation in Toronto, Canada. PLoS One 2010; 5: e10717
[90] Thompson KA, Pappachan JV, Bennett AM et al. Influenza aerosols in UK hospitals during the H1N1 (2009) pandemic-the risk of aerosol generation during medical procedures. PLoS One 2013; 8: e56278

[91] Canelli R, Connor CW, Gonzalez M et al. Barrier Enclosure during Endotracheal Intubation. N Engl ] Med 2020: doi:10.1056/ NEJMc2007589

[92] Braunlich J, Goldner F, Wirtz H. Nasal highflow eliminates CO2 from lower airways. Respir Physiol Neurobiol 2017; 242: 86-88

[93] Hui DS, Chow BK, Lo T et al. Exhaled air dispersion during high-flow nasal cannula therapy versus CPAP via different masks. Eur Respir J 2019; 53: doi:10.1183/13993003.02339-2018

[94] Kotoda M, Hishiyama S, Mitsui K et al. Assessment of the potential for pathogen dispersal during high-flow nasal therapy. J Hosp Infect 2019: doi:10.1016/j.jhin.2019.11.010

[95] Leung CCH, Joynt GM, Gomersall CD et al. Comparison of high-flow nasal cannula versus oxygen face mask for environmental bacterial contamination in critically ill pneumonia patients: a randomized controlled crossover trial. J Hosp Infect 2019; 101: 84-87

[96] He G, Han Y, Fang Q et al. [Clinical experience of high-flow nasal cannula oxygen therapy in severe corona virus disease 2019 (COVID-19) patients]. Zhejiang Da Xue Xue Bao Yi Xue Ban 2020; 49: 0

[97] Loeb M, McGeer A, Henry B et al. SARS among critical care nurses, Toronto. Emerg Infect Dis 2004; 10: 251-255

[98] Edwards DA, Man JC, Brand P et al. Inhaling to mitigate exhaled bioaerosols. Proc Natl Acad Sci U S A 2004; 101: 17383-17388

[99] Rochwerg B, Brochard L, Elliott MW et al. Official ERS/ATS clinical practice guidelines: noninvasive ventilation for acute respiratory failure. Eur Respir J 2017; 50: doi:10.1183/13993003.02426-2016

[100] World Health Organization. IMAI district clinician manual: hospital care for adolescents and adults: guidelines for the management of illnesses with limited-resources. 2020

[101] World Health Organization. Clinical management of severe acute respiratory infection (SARI) when COVID-19 disease is suspected: Interim guidance V 1.2. 2020

[102] Pediatric Acute Lung Injury Consensus Conference G. Pediatric acute respiratory distress syndrome: consensus recommendations from the Pediatric Acute Lung Injury Consensus Conference. Pediatr Crit Care Med 2015; 16: 428-439

[103] Riviello ED, Kiviri W, Twagirumugabe T et al. Hospital Incidence and Outcomes of the Acute Respiratory Distress Syndrome Using the Kigali Modification of the Berlin Definition. Am J Respir Crit Care Med 2016; 193: 52-59

[104] RKI. Ständiger Arbeitskreis der Kompetenz- und Behandlungszentren für Krankheiten durch hochpathogene Erreger am Robert KochInstitut. 2020

[105] Nehls W, Delis S, Haberland B et al. Handlungsempfehlung zur Therapie von Patient* innen mit COVID-19 aus palliativmedizinischer Perspektive 2.0. In: Beatmungsmedizin DGfPDGfPu ed 2020

[106] Rhodes A, Evans LE, Alhazzani W et al. Surviving Sepsis Campaign: International Guidelines for Management of Sepsis and Septic Shock: 2016. Crit Care Med 2017; 45: 486-552

[107] Pan C, Chen L, Lu C et al. Lung Recruitability in SARS-CoV-2 Associated Acute Respiratory Distress Syndrome: A Single-center, Observational Study. Am J Respir Crit Care Med 2020: doi:10.1164/ rccm.202003-0527LE

[108] Bellani G, Laffey JG, Pham T et al. Noninvasive Ventilation of Patients with Acute Respiratory Distress Syndrome. Insights from the LUNG SAFE Study. Am J Respir Crit Care Med 2017; 195: 67-77

[109] Frat JP, Ragot S, Coudroy R et al. Predictors of Intubation in Patients With Acute Hypoxemic Respiratory Failure Treated With a Noninvasive Oxygenation Strategy. Crit Care Med 2018; 46: 208-215 
[110] Frat JP, Thille AW, Mercat A et al. High-flow oxygen through nasal cannula in acute hypoxemic respiratory failure. N Engl J Med 2015; 372: 2185-2196

[111] Carteaux G, Millan-Guilarte T, De Prost N et al. Failure of Noninvasive Ventilation for De Novo Acute Hypoxemic Respiratory Failure: Role of Tidal Volume. Crit Care Med 2016; 44: 282-290

[112] Karagiannidis C, Bein T, Windisch W. Was hat sich seit Publikation der S3-Leitlinie "Invasive Beatmung und Einsatz extrakorporaler Verfahren" getan? Pneumologie 2020; 74: 46-49

[113] Harari SA, Vitacca M, Blasi F et al. Managing the Respiratory care of patients with COVID-19. 2020

[114] NHS. Guidance for the role and use of non-invasive respiratory support in adult patients with COVID-19 (confirmed or suspected). 2020

[115] Arabi YM, Fowler R, Hayden FG. Critical care management of adults with community-acquired severe respiratory viral infection. Intensive Care Med 2020; 46: 315-328

[116] Goh KJ, Choong MC, Cheong EH et al. Rapid Progression to Acute Respiratory Distress Syndrome: Review of Current Understanding of Critical Illness from COVID-19 Infection. Ann Acad Med Singapore 2020; 49: 1-9

[117] Du Y, Tu L, Zhu P et al. Clinical Features of 85 Fatal Cases of COVID19 from Wuhan: A Retrospective Observational Study. Am J Respir Crit Care Med 2020: doi:10.1164/rccm.202003-05430C

[118] Liang T. Handbook of COVID-19 Prevention and Treatment.

[119] Phua J, Weng L, Ling L et al. Intensive care management of coronavirus disease 2019 (COVID-19): challenges and recommendations. Lancet Respir Med 2020: doi:10.1016/s2213-2600(20)30161-2

[120] Wallet F, Schoeffler M, Reynaud M et al. Factors associated with noninvasive ventilation failure in postoperative acute respiratory insufficiency: an observational study. Eur J Anaesthesiol 2010; 27: $270-274$
[121] Antonelli M, Conti G, Moro ML et al. Predictors of failure of noninvasive positive pressure ventilation in patients with acute hypoxemic respiratory failure: a multi-center study. Intensive Care Med 2001; 27: $1718-1728$

[122] Bourke SC, Piraino T, Pisani L et al. Beyond the guidelines for non-invasive ventilation in acute respiratory failure: implications for practice. Lancet Respir Med 2018; 6: 935-947

[123] Duan J, Han X, Bai L et al. Assessment of heart rate, acidosis, consciousness, oxygenation, and respiratory rate to predict noninvasive ventilation failure in hypoxemic patients. Intensive Care Med 2017; 43: 192-199

[124] Guan L, Zhou L, Zhang J et al. More awareness is needed for severe acute respiratory syndrome coronavirus 2019 transmission through exhaled air during non-invasive respiratory support: experience from China. Eur Respir J 2020; 55: doi:10.1183/13993003.003522020

[125] Baker JG, Sovani M. Case for continuing community NIV and CPAP during the COVID-19 epidemic. Thorax 2020: doi:10.1136/thoraxjnl-2020-214913

[126] Alhazzani W, Moller MH, Arabi YM et al. Surviving Sepsis Campaign: Guidelines on the Management of Critically III Adults with Coronavirus Disease 2019 (COVID-19). Crit Care Med 2020: doi:10.1097| ccm.0000000000004363

[127] Wang Y, Lu X, Chen H et al. Clinical Course and Outcomes of 344 Intensive Care Patients with COVID-19. Am J Respir Crit Care Med 2020: doi:10.1164/rccm.202003-0736LE

[128] Mandell LA, Wunderink RG, Anzueto A et al. Infectious Diseases Society of America/American Thoracic Society consensus guidelines on the management of community-acquired pneumonia in adults. Clin Infect Dis 2007; 44: (Suppl. 02): S27-72 